\title{
Two Fusarium copper radical oxidases with high activity on aryl alcohols
}

\author{
Maria Cleveland ${ }^{1,2,3}$, Mickael Lafond ${ }^{1,4}$, Fan Roderick Xia ${ }^{1,2,3}$, Ryan Chung ${ }^{2}$, Paul Mulyk ${ }^{2}$, Jason E. Hein ${ }^{2}$ and \\ Harry Brumer ${ }^{1,2,3,5,6^{*}}$ (D)
}

\begin{abstract}
Background: Biomass valorization has been suggested as a sustainable alternative to petroleum-based energy and commodities. In this context, the copper radical oxidases (CROs) from Auxiliary Activity Family 5/Subfamily 2 (AA5_2) are attractive biocatalysts for the selective oxidation of primary alcohols to aldehydes. Originally defined by the archetypal galactose 6-oxidase from Fusarium graminearum, fungal AA5_2 members have recently been shown to comprise a wide range of specificities for aromatic, aliphatic and furan-based alcohols. This suggests a broader substrate scope of native CROs for applications. However, only $10 \%$ of the annotated AA5_2 members have been characterized to date.

Results: Here, we define two homologues from the filamentous fungi Fusarium graminearum and F. oxysporum as predominant aryl alcohol oxidases (AAOs) through recombinant production in Pichia pastoris, detailed kinetic characterization, and enzyme product analysis. Despite possessing generally similar active-site architectures to the archetypal FgrGalOx, FgrAAO and FoxAAO have weak activity on carbohydrates, but instead efficiently oxidize specific aryl alcohols. Notably, both FgrAAO and FoxAAO oxidize hydroxymethyl furfural (HMF) directly to 5-formyl-2-furoic acid (FFCA), and desymmetrize the bioproduct glycerol to the uncommon L-isomer of glyceraldehyde.

Conclusions: This work expands understanding of the catalytic diversity of CRO from AA5_2 to include unique representatives from Fusarium species that depart from the well-known galactose 6-oxidase activity of this family. Detailed enzymological analysis highlights the potential biotechnological applications of these orthologs in the production of renewable plastic polymer precursors and other chemicals.
\end{abstract}

Keywords: Copper radical oxidase, Aryl alcohol oxidase, Galactose oxidase, Biocatalysis, Metalloenzyme

\section{Background}

Our dependency on non-renewable resources and the associated environmental consequences pose as an existential crisis to human society $[1,2]$. One avenue to reduce consumption of fossil petroleum is to utilize biomass as a renewable, alternative carbon source. In this regard, the development of integrated biorefineries that produce multiple products, including fuels, chemicals,

*Correspondence: brumer@msl.ubc.ca

${ }^{1}$ Michael Smith Laboratories, University of British Columbia, 2185 East Mall, Vancouver, BC V6T 1Z4, Canada

Full list of author information is available at the end of the article and materials (collectively "bio-products") would advance the goal to lower net carbon emissions [3, 4]. In particular, harnessing the inherent chemical functionality of biomass constituents to produce high-value bio-products through selective derivatization is currently envisioned as a better value proposition than complete saccharification and fermentation to commodity fuels [5].

In nature, terrestrial biomass is efficiently transformed and degraded by fungi via a plethora of specialized enzymes that could be harnessed in biocatalytic processes for the industrial production of bio-products [6-8]. In particular, fungi have a rich history as sources of hydrolytic enzymes for biomass saccharification [9-12]. Fungi 
also produce a diversity of redox enzymes, which act on a wide range of substrates [13]. Notably, there is increasing interest in the use of redox enzymes to replace chemical oxidants, many of which generate hazardous waste co-products. Indeed, bio-oxidation reactions account for one-sixth of the biocatalysis performed industrially, including hydroxylation, Baeyer-Villiger catalysis, alcohol and amine oxidation, and other transformations [7, 14]. Presently, the majority of these transformations are performed by FAD- and NAD(P)-dependent enzymes, which require complex organic cofactors, and in the latter case, cofactor recycling strategies [6].

In contrast, copper radical oxidases (CROs) [15], have received considerably less attention regarding their potential as industrial biocatalysts $[7,16]$. CROs comprise Auxiliary Activity Family 5 in the CarbohydrateActive Enzymes (CAZy) classification, and thus share similar tertiary structures and active sites containing a mononuclear copper center [15, 17-19]. AA5 has been further divided into two subfamilies based on molecular phylogeny. Subfamily 1 (AA5_1) comprises (methyl)glyoxal oxidases (E.C. 1.2.3.15) that oxidize select aldehydes, likely via the hydrated gem-diol, to the corresponding carboxylic acid with concomitant reduction of $\mathrm{O}_{2}$ to $\mathrm{H}_{2} \mathrm{O}_{2}$ [20]. Subfamily 2 (AA5_2) contains the founding galactose oxidases (GalOx, E.C.1.1.3.9) [21-25] as well as the more recently discovered general alcohol oxidases (AlcOx, E.C. 1.1.3.13) $[18,26]$ and aryl alcohol oxidases (AAO, E.C. 1.1.3.7) [19], all of which convert the primary alcohol of the substrate to the corresponding aldehyde in an analogous two electron oxidation. The specific biological roles of CROs are currently unknown, although they have been speculated to play a role in oxidative lignocellulose degradation and have been linked to fungal pathogenesis $[15,27]$.

The archetypal galactose oxidase from the phytopathogen Fusarium graminearum ( $\mathrm{Fr} r \mathrm{GalOx}$ ) has been used in many biotechnological applications such as glycoprotein labeling [28-31], construction of lactose biosensors [32], chemo-enzymatic modification of galactose and galactosides [33], and complex polysaccharide modification for the development of functional materials [34-38]. As the only characterized member of AA5 for many years, FgrGalOx has been the subject of many protein engineering and directed evolution experiments to broaden substrate scope to include activity on glucose [39, 40], fructose [41], mannose [42], N-acetylglucosamine [42], secondary alcohols [43], amino alcohols [44] and benzyl alcohols [45]. Other studies have been performed to increase the catalytic efficiency of $\mathrm{FgrGalOx}$ [46-49]. Especially notable, a highly evolved variant of $\mathrm{FgrGalOx}$ was central to the recent industrial development of a biocatalytic synthesis of the drug islatravir [50]. Thus, there is significant scope to expand the application space of CROs to meet the need for new oxidation catalysts dependent on substrate range $[7,16,51,52]$.

The diversity of CROs from AA5 remains largely unexplored, but features a breadth of sequences from fungal sources that can be mined for potentially new industrial applications. Of the hundreds of publicly available putative AA5 sequences currently in the CAZy database [13], only ten AA5_2 members from this subfamily have been biochemically characterized, with the majority (five) characterized as galactose or galactoside oxidases (four from Fusarium species) [53-56]. In this context, we have recently revealed novel non-carbohydrate-active CROs in AA5_2 from the phytopathogenic fungus Colletotrichum graminicola: CgrAlcOx displays high activity on primary aliphatic, benzyl, and other unsaturated alcohols [18], while CgrAAO is most active on a range of benzyl alcohols and is also active on hydroxymethylfurfural (HMF, EC 1.1.3.47) [19].

Intrigued by this broader catalytic potential of AA5_2, we have used molecular phylogeny to guide the selection of two distinct homologs from $F$. graminearum and $F$. oxysporum for recombinant expression and biochemical characterization. Notably, both enzymes had low activity on carbohydrates, but displayed high activity on aryl alcohols, such as veratryl alcohol, and have considerable activity on HMF and oxidized congeners. Detailed enzyme kinetic and product analysis, together with molecular modeling of substrate recognition, allowed us to rationalize this specificity profile with regard to the composition of the active site.

\section{Results and discussion Bioinformatics}

Building upon our previous discovery of unique substrate specificities among Colletotrichum AA5_2 homologs $[18,19]$, we were keen to explore alternative homologs of AA5_2 members from Fusarium species, from which a number of galactose oxidases have been described $[53,54,56]$, including the archetypal FgrGalOx [17, 25, $57,58]$. A molecular phylogeny was generated to guide target selection, using 45 AA5_2 catalytic modules selected from the CAZy database [13], including previously characterized homologs from Fusarium and Colletotrichum (Fig. 1). We observed that a homolog from $F$. graminearum (GenBank XP_011322138) grouped into a strongly supported clade that was notably distant from that containing $\mathrm{FgrGalOx}$. This clade is also distinct from the early diverging clade comprising the Colletotrichum AlcOxs and AAO. To our knowledge, there are no biochemically characterized members of this clade [59], thus warranting further study. We also selected the homolog from F. oxysporum (GenBank XP_018246910) 


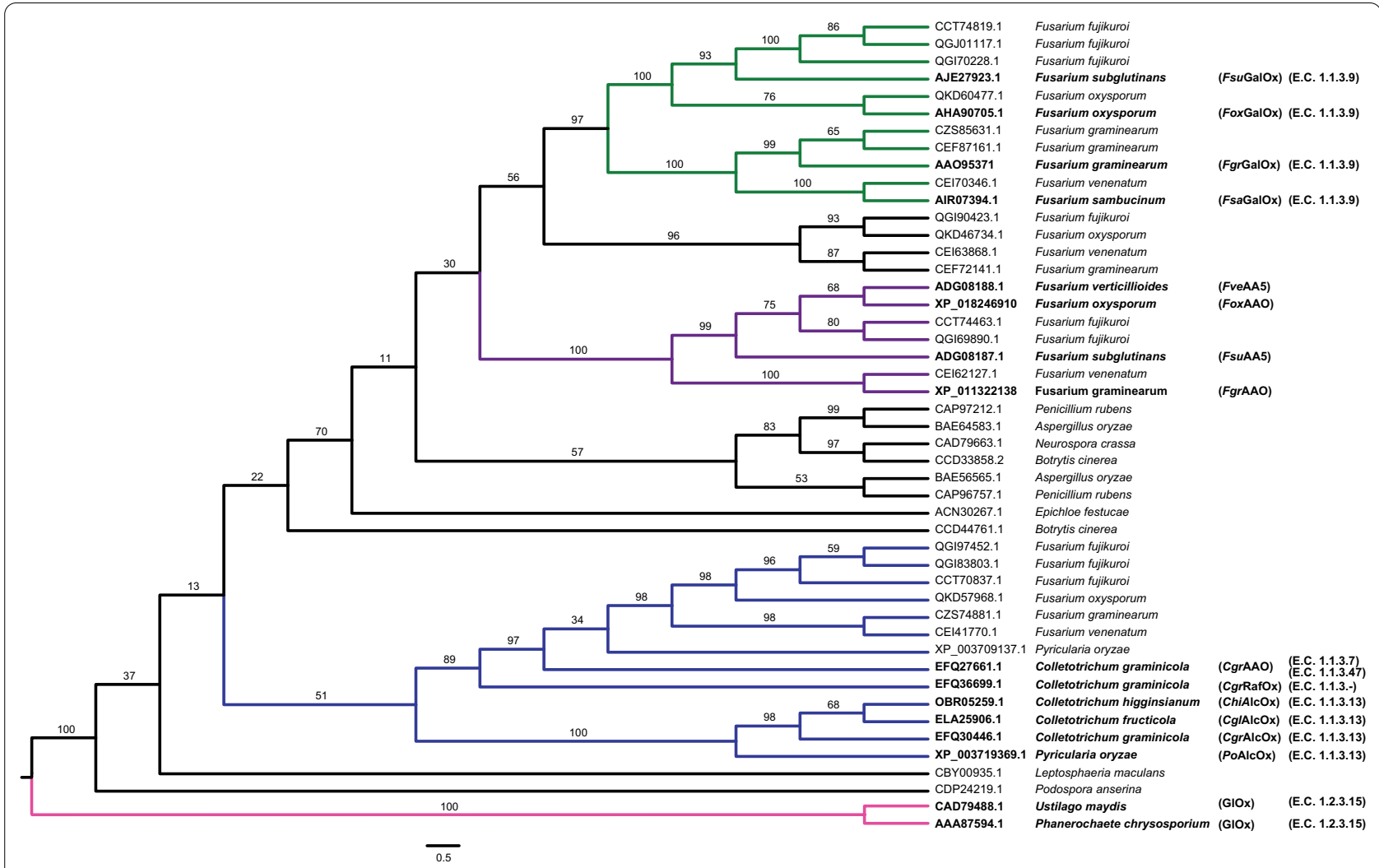

Fig. 1 Molecular phylogeny of 45 AA5_2 members. The sequences of two AA5_1 (methyl)glyoxal oxidase catalytic modules [60] were included as an outgroup to root the tree (highlighted in pink). Clades containing characterized Colletotrichum enzymes are highlighted in blue, FgrAAO and FoxAAO in purple and FgrGalOx in green. GenBank Accessions are given for all sequences from the public CAZy database (February 2021) with the genus and species names of source organisms with E.C. numbers also listed. Data from previous studies comprise AAO95371 (FgrGalOx) [17, 57, 58], AHA90705.1 (FoxGalOx) [54], AlR07394.1 (FsaGalOx) [53], AJE27923 (FsuGalOx) [56], ADG08188.1 and ADG08187.1 (FveAA5 and FsuAA5) [59], XP_011322138 and XP_018246910 (FgrAAO and FoxAAO, this study), EFQ27661.1 (CgrAAO) [19], EFQ30446 and ELA25906.1 (CgrAlcOx and CglAlcOx) [18], EFQ36699.1 (CgrRafOx) [55], OBR05259.1 (ChiAlcOx) and XP_003719369.1 (PoAlcOx) [26]

for characterization, as a second example from this clade. Hereafter, these homologs will be referred to as FgrAAO and FoxAAO, respectively, based on subsequent substrate specificity analysis (vide infra).

Concordant with this phylogeny, a protein sequence alignment of FgrAAO and FoxAAO revealed that they are highly similar (91\% pairwise identity, Additional file 1: Table S1). FgrAAO and FoxAAO have ca. $60 \%$ pairwise identity versus the AA5 archetype $\mathrm{FgrGalOx}[17$, 61 and with characterized GalOx from $F$. oxysporum, $F$. sambucinum and F. subglutinans $[53,54,56]$ (Fig. 1 and Additional file 1: Table S1). On the other hand, FgrAAO and FoxAAO have low sequence similarity with the characterized Colletotrichum AA5 members, CgrAlcOx and CgrAAO (ca. 50\% identity, Additional file 1: Table S1). Particularly notable, FgrAAO and FoxAAO share high sequence identity $(80 \%)$ with orthologs from $F$. verticillioides and $F$. subglutinans, which have been cloned but not characterized in recombinant form (Fig. 1 and Additional file 1: Table S1) [59].
It is worth underscoring that the phylogeny shown in Fig. 1 was calculated based on AA5 catalytic modules only, and that FgrAAO and FoxAAO have the same modular organization as $\mathrm{FgrGalOx}$, viz. an $\mathrm{N}$-terminal carbohydrate-binding module (CBM32) [62] in tandem with the AA5_2 module. In contrast, CgrAlcOx and CgrAAO lack an $\mathrm{N}$-terminal carbohydrate-binding module (Fig. 2). Detailed sequence analysis indicated that key activesite and secondary shell radical-stabilizing residues are largely conserved between FgrGalOx, FrrAAO and FoxAAO (Fig. 2). A notable exception is the Arg-to-Lys substitution in FrrAAO and FoxAAO corresponding to K330 in $\mathrm{FgrGalOx}$. Site-directed mutation of this residue in FgrGalOx has been shown to increase relative activities on fructose (in wild-type $F g r \mathrm{GalOx}$ ) [41] and mannose (in $\mathrm{M}_{1}$ variant) [42], thus highlighting a role in substrate specificity. Mutation of the active-site residues G195 and Q326 in FgrGalOx has been shown to improve protein stability [33] and alter substrate specificity [42], respectively, while the distal residues C383, Y436, and V494 


\section{A}

\begin{tabular}{|c|c|c|c|c|c|c|c|c|c|c|c|c|c|c|c|}
\hline \multirow{3}{*}{$\begin{array}{l}\text { Enzyme* } \\
\text { FgrGalOx }\end{array}$} & \multirow{3}{*}{$\begin{array}{c}\text { GenBank } \\
\text { Accession/PDB } \\
\text { ID } \\
\text { AAO95371 }\end{array}$} & \multicolumn{10}{|c|}{ Active Site Amino Acids } & \multirow{2}{*}{\multicolumn{3}{|c|}{\begin{tabular}{|l|} 
Distal Amino Acids \\
Catalytic efficiency
\end{tabular}}} & \multirow{3}{*}{\begin{tabular}{|l|} 
Modularity \\
CBM32-AA5
\end{tabular}} \\
\hline & & \multirow{3}{*}{\begin{tabular}{|c|}
$\begin{array}{c}\text { Radical } \\
\text { Stabilization } \\
\text { W290 } \\
\text { W292 }\end{array}$ \\
\end{tabular}} & \multicolumn{9}{|c|}{ Substrate Recognition/Active Site Cavity Shape } & & & & \\
\hline & & & F194 & G195 & Q326 & Y329 & R330 & Y405 & Q406 & P463 & F464 & C383 & Y436 & V494 & \\
\hline FgrAAO & XP_011322138 & & F195 & Q196 & E328 & Y331 & K332 & Y409 & Q410 & P469 & F470 & N386 & $\mathbf{N} 436$ & T500 & CBM32-AA5 \\
\hline FoxAAO & XP_018246910 & W292 & F195 & Q196 & E328 & Y331 & K332 & Y409 & Q410 & P469 & F470 & N386 & I436 & T500 & CBM32-AA5 \\
\hline $\mathrm{CgrAlcOx}$ & EFQ30446 & F138 & W39 & T40 & G172 & F174 & M173 & Y245 & T246 & L302 & F303 & C222 & K276 & N333 & AA5 \\
\hline CgraAO & EFQ27661 & Y333 & F239 & S329 & E369 & W372 & R373 & Y443 & T444 & V500 & F502 & C421 & G473 & N531 & AA5-Pan1 \\
\hline
\end{tabular}

\section{B}
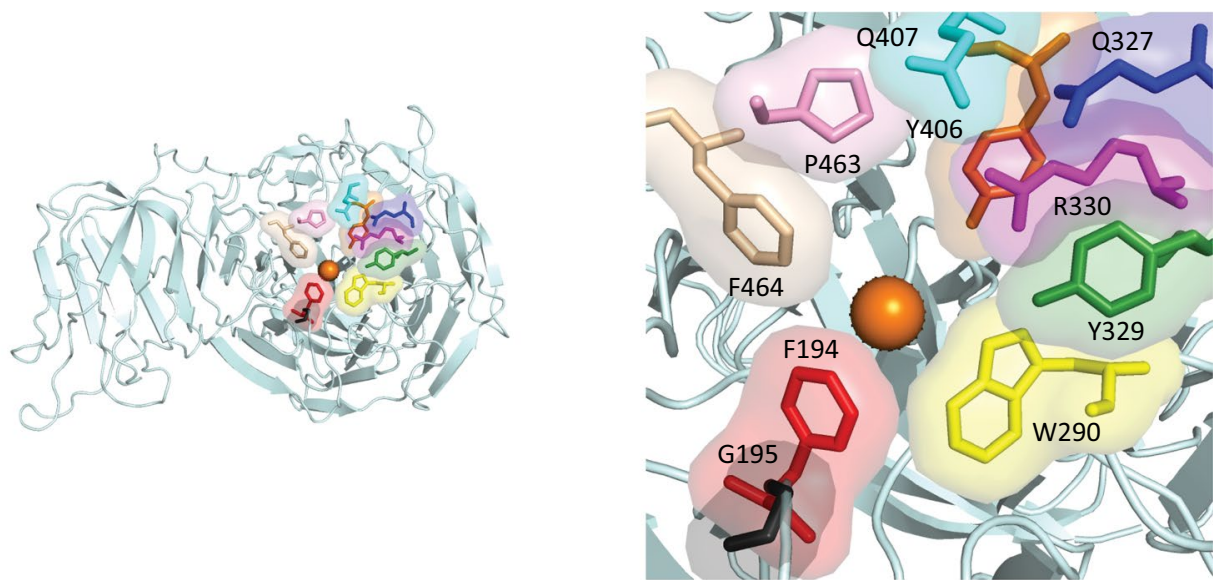

Fig. 2 Active site amino acids in AA5_2 members. A Key amino acid residues in the two candidate enzymes compared to other characterized AA5_2 copper radical oxidases. Non-conserved amino acids in relation to FgrGalOx are bolded. Fungal species: Fgr, Fusarium graminearum; Fox, Fusarium oxysporum; Cgr, Colletotrichum graminicola. B Active site of FgrGalOx. Left panel—full protein, right panel—zoom of active site. Colors are coordinated with amino acid residues in Panel A

have been implicated in affecting catalytic efficiency [46-49]. FgrAAO and FoxAAO are distinguished from the wild-type $\mathrm{FgrGalOx}$ in these positions and differ from each other at position Y436 (Fig. 2).

\section{Protein production and substrate screening}

cDNA corresponding to the mature, full-length FgrAAO and FoxAAO proteins comprising the $\mathrm{N}$-terminal CBM32 and C-terminal AA5_2 module (lacking the native signal peptide) were cloned into pPICZ $\alpha$-A vector in-frame with a Saccharomyces cerevisiae $\alpha$-factor secretion signal peptide and a C-terminal hexa-histidine tag. Both proteins were successfully produced in Pichia pastoris X33 and purified by a two-step IMAC-SEC protocol, with typical yields of $1 \mathrm{mg}$ of protein per $400 \mathrm{~mL}$ of expression medium. Notably, FoxAAO eluted as a single pure peak from the size exclusion column, whereas FgrAAO eluted as two peaks, the second of which contained pure enzyme, as determined by SDS-PAGE (Additional file 1: Figure S2). Both protein production levels are significantly lower (200-fold) than recombinant wildtype FgrGalOx [63] produced in P. pastoris. FgrAAO and FoxAAO $\left(2.5 \mathrm{mg} \mathrm{L}^{-1}\right)$ produce similarly to FoxGalOx (10.6 $\left.\mathrm{mg} \mathrm{L}^{-1}\right)$ [54] and had production values lower than wild-type $F g r G a l O x$ and $F g r G a l O x M_{1}$ constructs with histidine tags $\left(120 \mathrm{mg} \mathrm{L}^{-1}\right.$ and $110 \mathrm{mg} \mathrm{L}^{-1}$, respectively) [64], $C g r A l c O x\left(30-40 \mathrm{mg} \mathrm{L}^{-1}\right)$ [18] and $C g r \mathrm{AAO}$ (42.5 $\mathrm{mg} \mathrm{L}^{-1}$ ) [19].

In light of the sequence similarity of FgrAAO and FoxAAO to FgrGalOx (Additional file 1: Table S1), galactose was selected as an initial substrate for optimum $\mathrm{pH}$ and temperature determination. Both recombinant enzymes were active in the $\mathrm{pH}$ range from 5 to 10 , with bell-shaped $\mathrm{pH}$-rate profiles and optimum $\mathrm{pH}$ values of $c a .7 .5$ in sodium phosphate buffer (Additional file 1: Figure S3). This $\mathrm{pH}$ optimum is similar to other characterized AA5_2 members [18, 19, 53, 54, 65]. FgrAAO and FoxAAO were rapidly inactivated above $65{ }^{\circ} \mathrm{C}$ (Additional file 1: Figure S4). Additional stability assays indicated that both enzymes were stable at $30^{\circ} \mathrm{C}$ 
over ca. $6 \mathrm{~h}$, but lost a significant amount of activity with extended incubation at this and higher temperatures (Additional file 1: Figure S5). Overall, FgrAAO and FoxAAO appear to have lower thermostability than other AA5_2 members [18, 54].

FgrAAO and FoxAAO were then screened against a broad panel of primary alcohols, including carbohydrates, alkanols, and aryl alcohols of biological and synthetic relevance (Fig. 3 and Additional file 1: Table S2). Concordant with our initial activity assays, galactose and the galactosylated di- and trisaccharides melibiose, lactose, and raffinose were competent substrates of FgrAAO and FoxAAO, with specific activities up to $3 \mu \mathrm{mol} \mathrm{min}{ }^{-1} \mathrm{mg}^{-1}$ (Fig. 3 and Additional file 1: Table S2). In contrast, activity on xyloglucan or galactomannan, which bear terminal galactosyl (t-Gal) branch residues, was extremely limited. Strikingly, the highest monosaccharide activity was observed with mannose, while activity on the ketose, fructose, was comparable to that on galactose (Fig. 3 and Additional file 1: Table S2). Yet, very limited activity was detected on sucrose ( $\alpha$-Dglucopyranosyl- $(1 \rightarrow 2)-\beta$-D-fructofuranoside $) \quad$ and $\beta-(2 \rightarrow 1)$ fructo-oligosaccharides.
Primary alcohols, including a range of alkanols, diols, and alditols were generally not substrates for FgrAAO and FoxAAO, although glycerol was a competent substrate with a specific activity of $1.5 \mu \mathrm{mol} \mathrm{min}{ }^{-1} \mathrm{mg}^{-1}$ (one-half that of galactose). Although benzyl alcohol and cinnamyl alcohol were substrates for both enzymes, with cinnamyl alcohol preferred, the highest activities for FgrAAO and FoxAAO were observed with the substituted aryl alcohols 3-methoxybenzyl alcohol ( $m$-anisyl alcohol) and veratryl alcohol (3,4-dimethoxybenzyl alcohol). At the same time, 4-hydroxybenzyl alcohols (i.e., 4-hydroxybenzyl, vanillyl, and coniferyl alcohols) were not tolerated by either enzyme, and low activity on 4-methoxybenzyl alcohol ( $p$-anisyl alcohol) was also observed. FgrAAO and FoxAAO also exhibited activity on the furan substrates hydroxymethylfurfural (HMF), 5-(hydroxymethyl) furan-2-carboxylic acid (HMFCA) and 2,5-furandicarboxaldehyde (DFF) at levels similar to that of galactosyl substrates. This activity profile is notably distinct from that of the recently characterized CgrAAO [19], as well as CgrAlcOx [18]. In particular, CgrAAO does not show a significant preference for the substitution pattern on the aromatic ring of benzyl alcohols [19]. The regioselectivity

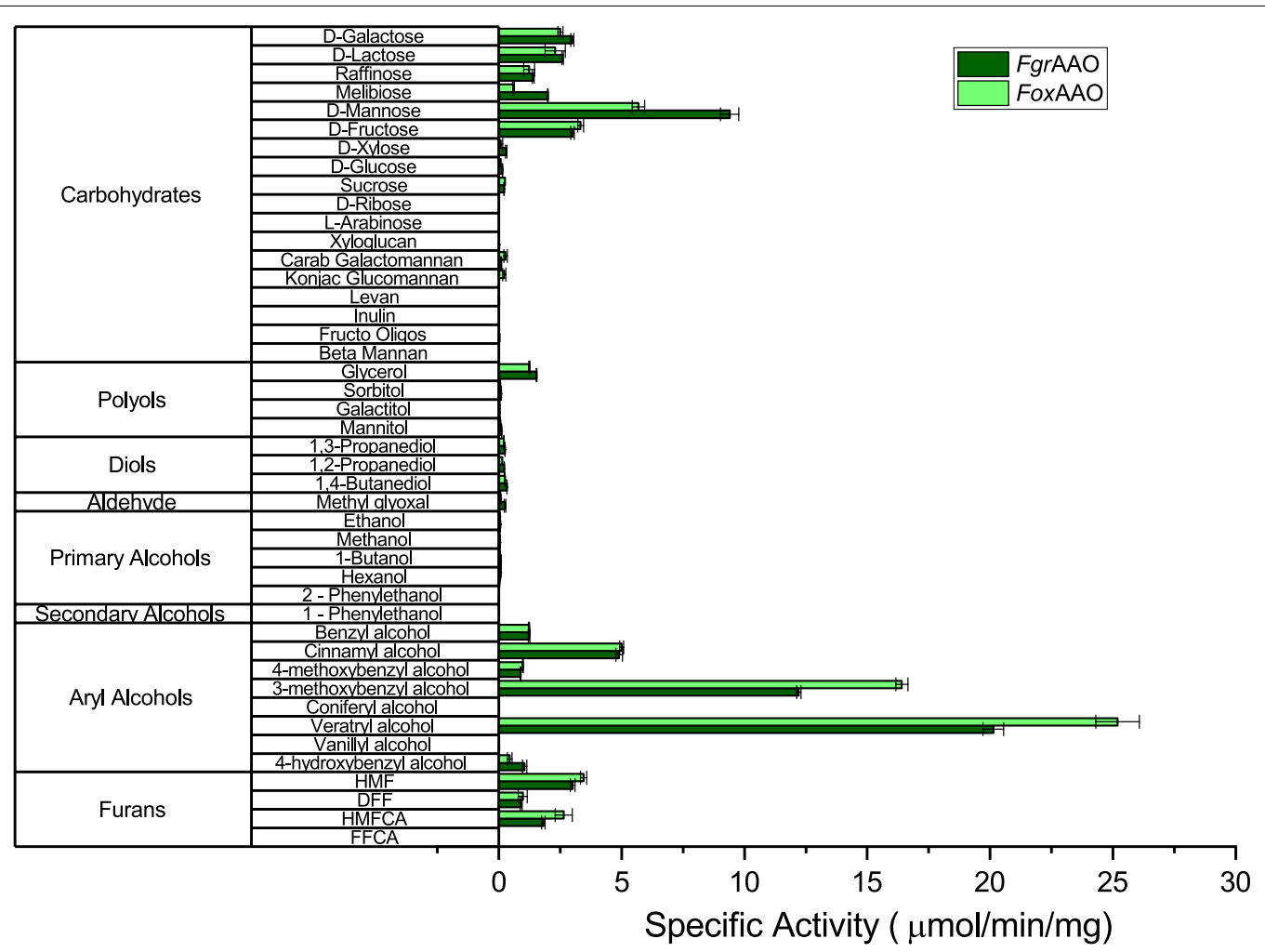

Fig. 3 Initial activity screens of FgrAAO and FoxAAO. Measurements were performed in triplicate at $25^{\circ} \mathrm{C}$ in $50 \mathrm{mM}$ sodium phosphate buffer, $\mathrm{pH}$ 7.5, using the HRP/ABTS assay. Activities were monitored using $300 \mathrm{mM}$ for carbohydrates, polyols, diols and primary alcohols, $2.5 \mathrm{mg} \mathrm{mL}^{-1}$ for polysaccharides, $30 \mathrm{mM}$ for benzyl alcohol and galactitol, $5 \mathrm{mM}$ for methyl glyoxal, aryl alcohols and furans and $10 \mathrm{mM}$ for secondary alcohols. Reactions were started with the addition of 6 pmol-1 nmole of purified enzyme (Additional file 1: Table S2) 
of FgrAAO and FoxAAO is similar to the engineered FgrGalOx variant $\mathrm{M}_{3-5}$, which has 1.4-fold higher activity on 3-methoxybenzyl alcohol than on 4-methoxybenzyl alcohol [45].

\section{Michaelis-Menten kinetics and product analysis}

The results of our initial activity screen, in particular the predominant activity on 3-methoxybenzyl alcohol and veratryl alcohol, suggests that both enzymes may be best named as aryl alcohol oxidases (EC 1.1.3.7). However, this is not unequivocal as select carbohydrates and furans exhibited significant specific activity values at the substrate concentrations tested. To further define the substrate specificity of FgrAAO and FoxAAO, MichaelisMenten kinetic analysis was performed to determine $k_{\text {cat }}$ and $K_{\mathrm{M}}$ values for the lead substrates (Additional file 1: Figure S6 and Table 1). In these cases, assays of FgrAAO and FoxAAO were performed at $35^{\circ} \mathrm{C}$ to balance optimal enzyme activity with short-term stability (vide supra).

This analysis revealed that the monosaccharides galactose, mannose, and fructose, and the triol glycerol, are in fact poor substrates for both FgrAAO and FoxAAO. Although $k_{\text {cat }}$ values for these substrates are comparable to those of benzyl alcohols and furans, $K_{\mathrm{M}}$ values are in the 0.5-2.0 $\mathrm{M}$ range. This indicates poor active-site affinity and selectivity for these polyhydroxylated compounds, with $k_{\mathrm{cat}} / K_{\mathrm{M}}$ values only in the range $10-80 \mathrm{M}^{-1} \mathrm{~s}^{-1}$. Specifically, galactose was indeed a poor substrate for both FgrAAO and FoxAAO, displaying 1000-fold lower $k_{\text {cat }} / K_{\mathrm{M}}$ values than the canonical FgrGalOx [41], due to ca. 25-fold higher $K_{\mathrm{M}}$ values and $c a$. 50 -fold lower $k_{\text {cat }}$ values. In contrast, $k_{\mathrm{cat}} / K_{\mathrm{M}}$ values for competent benzyl alcohol substrates are in the range $10^{3}-10^{4} \mathrm{M}^{-1} \mathrm{~s}^{-1}$, while that of HMF is $c a$. $2000 \mathrm{M}^{-1} \mathrm{~s}^{-1}$ for both enzymes. In these cases, this is largely due to $K_{\mathrm{M}}$ values in the millimolar range (Table 1).

\section{Aryl alcohol oxidation}

Benzyl alcohols The much higher specificity constants of FgrAAO and FoxAAO on benzyl and furan alcohols validates the designation of these enzymes as aryl alcohol oxidases (EC 1.1.3.7). Concordant with their grouping in the same phylogenetic clade (Fig. 1), both enzymes displayed similar catalytic parameters on those substrates for which detailed kinetics were performed, with the highest activities toward veratryl alcohol, 3-methoxybenzyl ( $m$-anisyl) alcohol, and cinnamyl alcohol (Table 1$)$. $k_{\text {cat }} / K_{\mathrm{M}}$ values for these substrates were also similar to those observed for CgrAAO [19] and FgrGalOx [66], for which these are secondary substrates (Additional file 1: Table S4). Distinctly, the broad-spectrum aliphatic/ aryl alcohol oxidase $\mathrm{CgrAlcOx}$ [18] is ca. 2 orders of

Table 1 Substrate specificity of FgrAAO and FoxAAO

\begin{tabular}{|c|c|c|c|c|c|c|}
\hline \multirow[t]{2}{*}{ Substrate } & \multicolumn{3}{|l|}{ FgrAAO } & \multicolumn{3}{|l|}{ FoxAAO } \\
\hline & $K_{M}(\mathrm{mM})$ & $k_{\text {cat }}\left(\mathrm{s}^{-1}\right)$ & $k_{\mathrm{cat}} / K_{M}\left(\mathrm{M}^{-1} \mathrm{~s}^{-1}\right)$ & $K_{M}(\mathrm{mM})$ & $k_{\text {cat }}\left(s^{-1}\right)$ & $k_{\mathrm{cat}} / K_{M}\left(\mathrm{M}^{-1} \mathrm{~s}^{-1}\right)$ \\
\hline \multicolumn{7}{|l|}{ Carbohydrates } \\
\hline Galactose & $1700 \pm 150$ & $21 \pm 1.0$ & 12 & $1600 \pm 150$ & $23 \pm 1.2$ & 14 \\
\hline Galactose & $450 \pm 74$ & $36 \pm 1.2$ & 79 & $620 \pm 57$ & $19 \pm 0.35$ & 31 \\
\hline Fructose & $460 \pm 91$ & $9.7 \pm 0.55$ & 21 & $510 \pm 82$ & $16 \pm 0.72$ & 31 \\
\hline \multicolumn{7}{|l|}{ Polyols } \\
\hline Glycerol & $2200 \pm 360$ & $17 \pm 1.2$ & 7.7 & $2700 \pm 403$ & $24 \pm 1.6$ & 8.8 \\
\hline \multicolumn{7}{|l|}{ Aryl alcohols } \\
\hline Benzyl alcohol & $86 \pm 12$ & $37 \pm 2.8$ & 430 & $30 \pm 19$ & $31 \pm 4.2$ & $1000(350 \pm 20)^{a}$ \\
\hline Cinnamyl alcohol & n.d. ${ }^{b}$ & n.d. ${ }^{b}$ & 3000 & n.d. ${ }^{b}$ & n.d. ${ }^{b}$ & 3200 \\
\hline 4-Methoxybenzyl (p-anisyl) alcohol & $59 \pm 7.2$ & $32 \pm 1.8$ & 540 & $51 \pm 12$ & $34 \pm 2.9$ & 290 \\
\hline 3-Methoxybenzyl (m-anisyl) alcohol & $6.5 \pm 1.5$ & $52 \pm 1.5$ & 8000 & $6.7 \pm 0.59$ & $34 \pm 1.7$ & 5100 \\
\hline 3,4-Dimethoxybenzyl (veratryl) alcohol & $3.7 \pm 0.75$ & $41 \pm 4.0$ & 11000 & $3.0 \pm 0.24$ & $25 \pm 1.2$ & 8300 \\
\hline \multicolumn{7}{|l|}{ Furans } \\
\hline HMF & $14 \pm 2.6$ & $29 \pm 1.7$ & 2100 & $17 \pm 4.9$ & $26 \pm 2.6$ & 1500 \\
\hline DFF & $10 \pm 2.9$ & $3.6 \pm 0.27$ & 360 & $3.7 \pm 1.0$ & $1.4 \pm 0.13$ & 380 \\
\hline HMFCA & $4.4 \pm 0.90$ & $3.8 \pm 0.33$ & 860 & $3.1 \pm 0.31$ & $5.2 \pm 0.14$ & 1700 \\
\hline
\end{tabular}

Errors represent the standard deviation from the mean values

${ }^{a} K_{\mathrm{M}}, k_{\mathrm{cat}}$, and $k_{\mathrm{cat}} / K_{\mathrm{M}}$ values calculated from fitting of the standard Michaelis-Menten equation to the data. Value in parentheses is the $k_{\mathrm{cat}} / K_{\mathrm{M}}$ value obtained from a linear fit to the data in the substrate range 1-50 mM. Fitting of the data with a modified Michaelis-Menten equation accounting for substrate inhibition was unsuccessful due to very high errors on individual parameters (see Additional file 1: Figure $S 6$ )

${ }^{\mathrm{b}}$ Individual $K_{\mathrm{M}}$ and $k_{\text {cat }}$ values not determinable due to substrate solubility limitations; $k_{\mathrm{cat}} / K_{\mathrm{M}}$ values obtained from slope of linear $\mathrm{v}_{0}$ versus [S] plots (Additional file 1 : Figure S6) 
magnitude more efficient than FgrAAO and FoxAAO on benzyl and cinnamyl alcohols, but does not oxidize other substrates of these enzymes, i.e., 4-methoxybenzyl alcohol (p-anisyl alcohol) and 4-hydroxybenzyl alcohol (Fig. 3 and Table 1). Together, specific activity and Michaelis-Menten kinetic data for FrrAAO and FoxAAO indicate that these enzymes favor 3-methoxy substitutions on the benzyl ring, and strongly disfavor substrates with 4-hydroxy substitutions (Fig. 3 and Table 1).

In the absence of an enzyme-substrate complex structure, it is presently unclear how a balance of electronic (e.g., the Hammett substituent constants for 3-methoxybenzyl, 4-methoxybenzyl, and veratryl alcohols are $+0.12,-0.27$, and -0.15 , respectively [67]) and steric effects (e.g., specific recognition of the 3-methoxy group) dictate the observed specificities. Interestingly, the R330K mutant of FgrGalOx showed a 63-fold decrease in activity on 3-methoxybenzyl alcohol compared to WT FgrGalOx [41]. This result juxtaposes our current observations that FgrAAO and FoxAAO natively possess an R330K mutation, yet exhibit a twofold increase in catalytic efficiency on 3-methoxybenzyl alcohol compared to WT FgrGalOx. These differences might be explained by the additional Q326E substitution that may make the FgrAAO and FoxAAO active sites more accessible to the methoxy-substituted substrate.

Furans The observation of demonstrable 5-(hydroxymethyl) furfural oxidation by FrrAAO and FoxAAO is also consistent with the assignment of these enzymes as aryl alcohol oxidases (see EC 1.1.3.47 vs. EC 1.1.3.7). The conversion of HMF from biomass sources into the bis-functional polymer precursors DFF and FDCA is of significant contemporary interest $[68,69]$. Select oxidases are capable of sequential oxidation of HMF to the various intermediates shown in Fig. 4 [14, 70-74]. Hence, we analyzed the reaction kinetics and products of FgrAAO and FoxAAO in each of these steps.

FgrAAO and FoxAAO display similar specificity constants on HMF to the eponymous bacterial HMF oxidase (a GMC superfamily oxidoreductase) [73], and exhibit higher specificity constants than other enzymes with HMF oxidase activity, including some glyoxal oxidases from AA5_1 (Additional file 1: Table S5) [70, 71, 74]. However, the recently reported CgrAAO [19] has tenfold higher activity on HMF than both FgrAAO and FoxAAO (Additional file 1: Table S5).

Product analysis by ${ }^{1} \mathrm{H}$-NMR spectroscopy following extended incubation with HMF revealed a product mixture of DFF and FFCA (Additional file 1: Figure S7), consistent with the initial formation of DFF and subsequent oxidation to FFCA, presumably via the aldehyde hydrate $[20,74]$. Indeed, the conversion of DFF to FFCA was directly demonstrated by initial-rate kinetics and

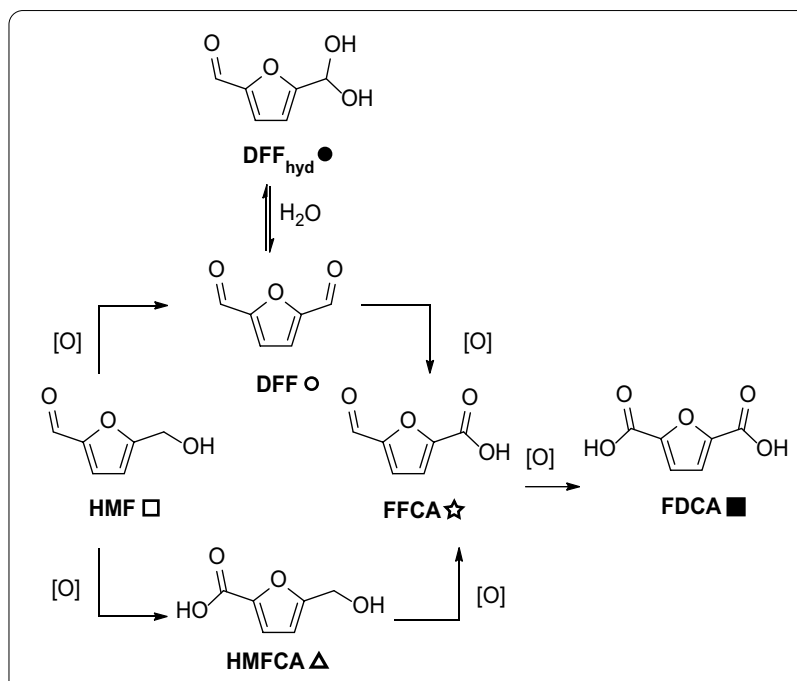

Fig. 4 HMF oxidation. [O] represents a generic oxidant. The symbols next to each compound are used to denote the corresponding peaks in the NMR spectra comprising Additional file 1: Figures S7-S9

Table 2 Percent conversion of HMF, DFF and HMFCA by FgrAAO and FOXAAO

\begin{tabular}{lll}
\hline Substrate & $\begin{array}{l}\text { FgrAAO } \\
\text { Products (\% conversion) }\end{array}$ & $\begin{array}{l}\text { FoxAAO } \\
\text { Products (\% conversion) }\end{array}$ \\
\hline HMF & DFF (69\%), FFCA (31\%) & DFF (76\%), FFCA (24\%) \\
DFF & FFCA (49\%) & FFCA (51\%) \\
HMFCA & FFCA (84\%) & FFCA (96\%) \\
FFCA & $0 \%$ & $0 \%$ \\
\hline
\end{tabular}

product analysis, although this oxidation step was considerably slower (Table 2 and Additional file 1: Figure S8). Furthermore, ${ }^{1} \mathrm{H}$ NMR analysis following the incubation of FgrAAO or FoxAAO with HMF at $1.5 \mathrm{~h}$ and $3 \mathrm{~h}$ did not indicate the formation of HMFCA, which argues against the lower pathway shown in Fig. 4. Neither FgrAAO nor FoxAAO was able to oxidize FFCA to FDCA under the conditions tested, perhaps due to the low degree of hydration of FFCA compared with DFF [74]. Furfural was also not oxidized by either enzyme in overnight reactions. Interestingly, HMFCA was also a good substrate for FgrAAO and FoxAAO, albeit with lower $k_{\text {cat }}$ and $K_{\mathrm{M}}$ values than HMF, but with significant conversion to FFCA in extended incubations (Table 2 and Additional file 1: Figure S9). In total, the specificity profiles of FgrAAO and FoxAAO are significantly different than those of other oxidases that are active on HMF and its derivatives [70-74], as summarized in Additional file 1: Table S5.

It is important to note that FgrAAO and FoxAAO are both able to convert HMF to FFCA, which is a step 
further than CgrAAO [19]. The bacterial HMF oxidase is able to convert HMF fully to FFCA as well, but its use in industry may be hindered by its cofactor dependent mechanism [73, 75-77]. Full enzymatic conversion of HMF to FDCA is ideal, but FgrAAO and FoxAAO show the possibility of an extension of current biocatalytic processes to FFCA with a single enzyme, instead of a complex co-factor dependent enzymatic cascade. Furthermore, FFCA itself has been used as precursor for biofuels, surfactants and resins [78].

\section{Saccharide oxidation}

As indicated above, monosaccharides, and galactose in particular, are comparatively poor substrates for FgrAAO and FoxAAO. Nonetheless, the observation of activity on galactose, mannose, and fructose deserves further comment. As listed in Table 1, the hexopyranoses galactose and mannose exhibit similar $k_{\text {cat }}$ values, with the apparently greater selectivity for mannose originating from a ca.four-fold lower $K_{\mathrm{M}}$ value. The activity on fructose is likewise weak, but of particular interest as this 2-ketose presents two potentially oxidizable primary hydroxyl groups in the predominant furanose form.

Galactose Although the molecular basis for the specificity difference between FraAO and FoxAAO and the archetypal FgrGalOx is unclear in the absence of any three-dimensional substrate or product complexes of AA5 members [17-19, 41, 42, 47, 57, 79, 80], sequence analysis and molecular modeling provides some insight. In particular, there is literature precedent for docking ligand structures into models of AA5_2 variants for activity analysis $[40,81]$.
Foremost, substitution of R330 with lysine in $\mathrm{FgrGa}$ $1 \mathrm{Ox}$ has been shown to dramatically decrease catalytic efficiency towards galactose through a ninefold increase in $K_{\mathrm{M}}$ and a fivefold decrease in $k_{\text {cat }}$ (Additional file 1: Table S3) [41]. This arginine, which is likewise replaced by lysine in FgrAAO and FoxAAO (Fig. 2), has also been speculated to be involved in hydrogen bonding to the $\mathrm{OH}$ groups at $\mathrm{C} 3$ and $\mathrm{C} 4$ of galactose by $\mathrm{FgrGalOx}$ [39]. Molecular modeling (Fig. 5) supported this proposal and indicated that $\mathrm{R} 330$ is positioned in $\mathrm{FgrGalOx}$ (PDB ID 1GOF) [17] to make two $\mathrm{H}$-bonds with $\mathrm{C} 3-\mathrm{OH}$ and C4-OH (1.8 and 2.4 $\AA$, respectively).

In contrast, when galactose is docked into a Phyre2 homology model of FgrAAO (based on FgrGalOx, PDB ID 2VZ1, as the template; $63 \%$ i.d., confidence value 100.0), only one potential $\mathrm{H}$-bond is predicted between $\mathrm{K} 330$ and the $\mathrm{C} 3-\mathrm{OH}$ of galactose $(2.0 \AA)$. Although hypothetical, these structures implicate variation of this residue as a carbohydrate specificity determinant among AA5_2 members. Notably, CgrAlcOx and CgrAAO, which have similarly low activity on galactose as FgrAAO and FoxAAO, also have a residue other than lysine at this position (Fig. 2). Furthermore, FgrAAO and FoxAAO have catalytic efficiencies on galactose that are more similar to the FgrGalOx mutant Des 3-2 (Q326E, Y329K and R330K) [40] (Additional file 1: Table S3), highlighting the importance of E326 and K330, which are both found natively in the homologs. The combination of mutations at distal positions (C383, Y436 and V494) might also contribute to the lower activity of FgrAAO and FoxAAO, as these residues have been implicated in changing the
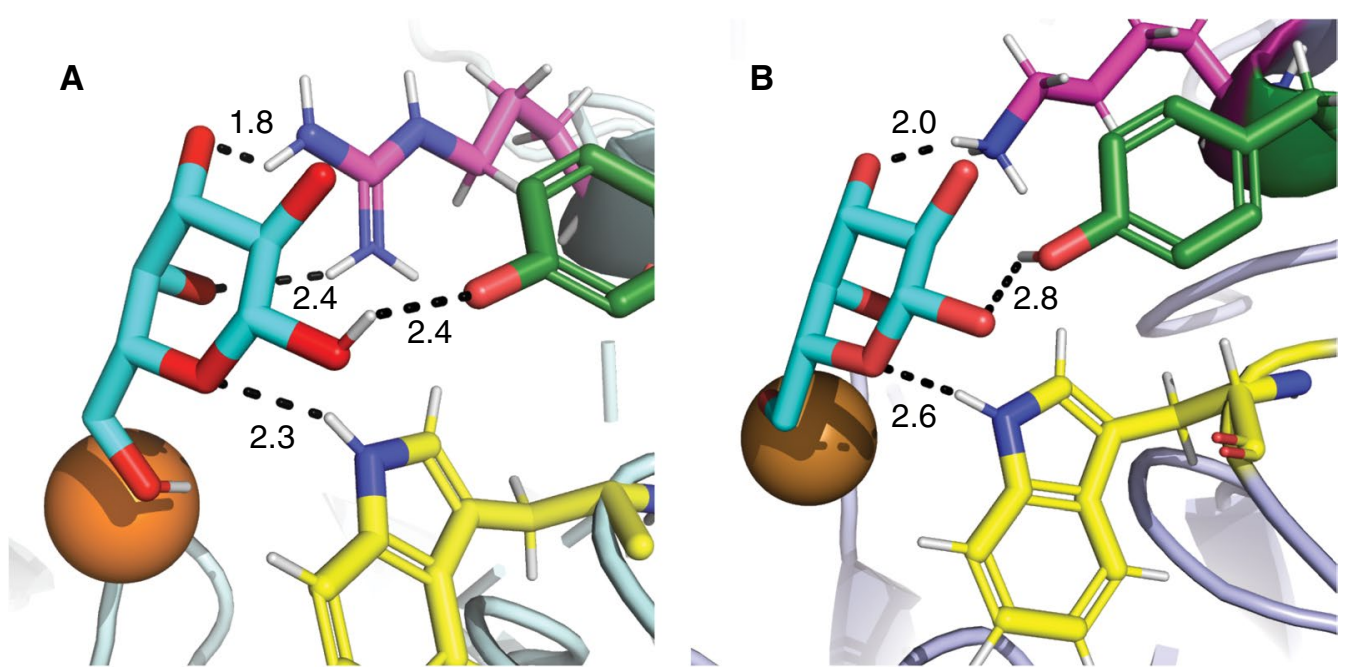

Fig. 5 Molecular docking of galactose (cyan) in FgrGalOx (PDB ID 1GOF) [17] (A) and a Phyre2 homology model of FgrAAO (B) using AutoDock Vina as implemented in Chimera. Copper (dark orange), W290 (yellow), Y329 (green), R330/K330 (magenta). Ligand coordination is indicated, specifying the distances (black) 
catalytic efficiency towards galactose (Additional file 1: Table S3) [46-49].

Mannose The differences in catalytic constants between galactose and mannose are slight, and are thus difficult to rationalize. However, it is worth noting that this is the first report, to our knowledge, of an AA5_2 member that demonstrates a higher native catalytic efficiency on a non-galactosyl carbohydrate. The wild-type FgrGalOx has no reported activity on mannose while the engineered variants $M_{1}$ and $M_{3}$ have relatively low specific activity compared to FraAO and FoxAAO on this monosaccharide [42, 49]. Furthermore, the enzymes presented in this study have a twofold higher catalytic efficiently that the $F g r G a l O x$ mutant $\mathrm{H}_{1}$ (Additional file 1: Table S3) [42]. These similarities could be caused by the analogous R330K substitution that is also present in the $\mathrm{H}_{1}$ [42] and $\mathrm{M}_{3}$ variants [42, 49]. Our attempts to model the binding of mannose to $\mathrm{Fr} r \mathrm{GalOx}$ and FgrAAO were inconclusive, precluding further discussion.

Fructose The only other enzyme from AA5_2 with the ability to oxidize fructose is the engineered variant FgrGalOx R330K [41], versus which FgrAAO and FoxAAO have comparably low activities (Additional file 1: Table S3). Nonetheless, this raises the question of which of the primary hydroxyl groups of fructose might be oxidized by FgrAAO and FoxAAO. Hence, we synthesized methyl $\beta$-D-fructopyranoside (1), methyl $\beta$-Dfructofuranoside (2) and methyl $\alpha$-D-fructofuranoside (3) (Additional file 1: Figures S10-11) by Fisher glycosylation [82] to eliminate complications due to mutarotation of the free sugar (Fig. 6).

1D $\left({ }^{1} \mathrm{H},{ }^{13} \mathrm{C}\left\{{ }^{1} \mathrm{H}\right\}\right)$ and 2D NMR (HSQC and HMBC) spectroscopy revealed that the two enzymes produced identical oxidation products (Fig. 7, Additional file 1: Tables S6-S7 and Figures S12-17). The reaction of methyl $\beta$-D-fructopyranoside (1) with FgrAAO and FoxAAO resulted in $19 \%$ and $17 \%$ conversion, respectively, as estimated by integration of ${ }^{1} \mathrm{H}$ NMR spectra. The only product observed in both cases was the hydrated aldehyde (7), as confirmed by detailed $1 \mathrm{D}$ and 2D NMR analysis (Figs. 7, Additional file 1: S12 and S15A-17A). Specifically, no aldehyde signal was observed in the range 9-10 ppm in ${ }^{1} \mathrm{H}$ NMR spectra, while a peak at $5.17 \mathrm{ppm}$ corresponding to the $\mathrm{C}-\mathrm{H}$ of a gem-diol [83] correlated to the quaternary carbon at $\mathrm{C} 2$, thus confirming the site of oxidation as the primary hydroxyl group of $\mathrm{C} 1$ (Additional file 1: Figures S15A and S17A). Turning our attention to the furanosides, methyl $\beta$-D-fructofuranoside (2) was converted to a single product (8) (Fig. 7, and Additional file 1: Figs. S13, S15B-17B) by FgrAAO or FoxAAO with $16 \%$ and $11 \%$ conversion, respectively. In these cases, a distinct doublet was observed at $4.85 \mathrm{ppm}$, which was attributed to the $\mathrm{C}-\mathrm{H}$ of a hydrated aldehyde. This doublet correlated to $\mathrm{C} 5$ in the HMBC spectrum, signifying that the primary hydroxyl of $\mathrm{C} 6$ was the site of oxidation of methyl $\beta$-D-fructofuranoside (Additional file 1: Figures S15B-17B).

On the other hand, the incubation of methyl $\alpha$-Dfructofuranoside (3) with FrrAAO or FoxAAO showed no indication of product formation (Additional file 1: Figures S14 and S15C-S17C). Thus, to further explore potential steric and stereochemical factors effecting enzymatic oxidation, 2,5-anhydro-D-glucitol (4) and 2,5-anhydro-D-mannitol (5) were tested as analogs of methyl $\alpha$-D-fructofuranoside and methyl $\beta$-D-fructofuranoside, respectively. Notably, no oxidation was observed with 2,5-anhydro-glucitol, however $6 \%$ oxidation was observed for 2,5-anhydro-mannitol, which is concordant with our observations with the methyl fructofuranosides. The low degree of conversion of 2,5-anhydro-mannitol made full spectral assignment challenging, however, we were able to observe correlation peaks in the HSQC and HMBC (Additional file 1: Figure S18), which were consistent with oxidation of a single primary hydroxyl group to an aldehyde that was subsequently hydrated to the gem-diol (9). In this context, it is important to note both primary hydroxyl groups of 2,5-anhydro-mannitol are equivalent, due to $C 2$ symmetry.

To assist in rationalizing these results, we modeled the binding of the three methyl fructosides $(\mathbf{1}-\mathbf{3})$ to a structural homology model of FgrAAO. A structural model was obtained for methyl $\beta$-D-fructopyranoside (1) with $\mathrm{C} 1-\mathrm{OH}$ oriented towards the copper and the methoxy group positioned toward an active site pocket containing P463, Y405 and K330 (Fig. 8). However, in this model, Tyr272 was $3.7 \AA$ away from the protons on the primary alcohol, suggesting a catalytically inactive pose. Using the same grid search area, a productive complex with methyl $\beta$-D-fructofuranoside (2) was obtained, in which the $\mathrm{C} 6-\mathrm{OH}$ was pointing towards the copper center and the anomeric methoxy group was pointing away from the substrate recognition residues and towards F464 and F194 (Fig. 8). In this model, the catalytic Tyr272 was located at a reasonable distance away from the abstractable hydrogen $(2.0 \AA)$. Most notably, the alternate structure, with the $\mathrm{C} 1-\mathrm{OH}$ oriented towards the copper, was not observed by modeling. Although hypothetical, these results are consistent with our experimental product analysis (Fig. 6). When docking was attempted with methyl $\alpha$-D-fructofuranoside (3), only one model was produced with the methoxy pointed towards the copper center, which represents a non-productive binding mode and is consistent with experimental results (Fig. 8). Notably, this pose constitutes a flip of the furanose ring relative to that observed for methyl $\beta$-D-fructofuranoside, which places C-6 distal from the copper center. Together, 
<smiles>CO[C@]1(CO)OC[C@@H](O)[C@H](O)[C@H]1O</smiles>

1

[O] FgrAAO<smiles>CC1(C(=O)O)OC[C@@H](O)[C@H](O)C1O</smiles>

methyl $\beta$-D-fructopyranoside<smiles>CO[C@]1(CO)OC(CO)[C@@H](O)C1O</smiles><smiles>CO[C@@]1(CO)OC(C(O)O)[C@@H](O)[C@H]1O</smiles>

methyl $\beta$-D-fructofuranosides<smiles>CO[C@@]1(CO)OC(CO)[C@@H](O)C1O</smiles>

\section{$\stackrel{\text { [O] FgrAAO }}{\longrightarrow}$}

methyl $\alpha$-D-fructofuranoside<smiles>CC(C)(C)[Ge](C)(C)O[Na]</smiles>

2,5-anhydro-glucitol<smiles>OC[C@H]1O[C@H](CO)[C@H](O)[C@@H]1O</smiles>

2,5-anhydro-mannitol

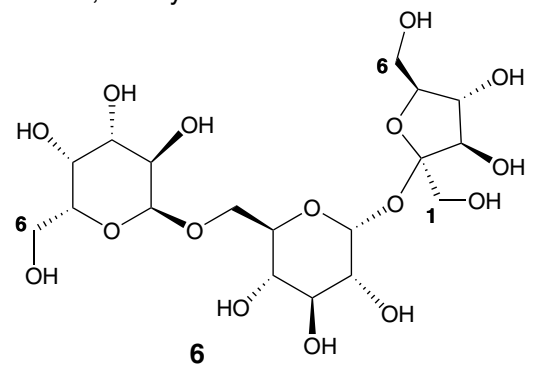

raffinose $[\beta-D$-fructofuranosyl-O- $\alpha-D$ glucopyranosyl-(1->6)- $\alpha$-D-galactopyranoside]<smiles>OC[C@H]1OC(C(O)O)[C@@H](O)[C@H]1O</smiles>

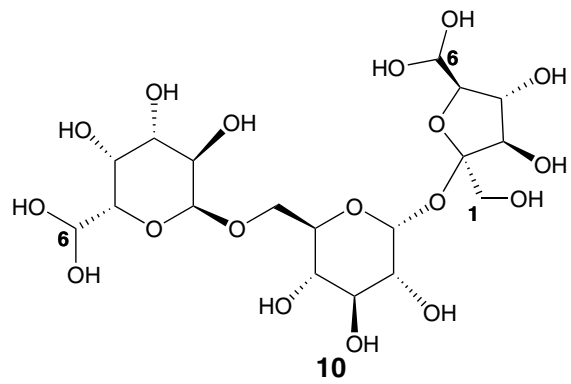

Bis-oxidized raffinose

Fig. 6 Summary of observed hydrated aldehyde (gem-diols) products from the oxidation of methyl fructosides, anhydro sugars and raffinose by FgrAAO

these models suggest that binding modes that direct the anomeric methyl group into the protein are disfavored, thus rationalizing the observed specificity.

In light of the observed 6-O-oxidase activity on methyl $\beta$-D-fructofuranoside, as well as the oxidase activity observed on the classical GalOx substrate raffinose $[\beta$-D-fructofuranosyl-O- $\alpha$-Dglucopyranosyl-( $1 \rightarrow 6)-\alpha$-D-galactopyranoside] (Fig. 3), the potential for multiple oxidations of the trisaccharide was investigated by NMR spectroscopy. Thus ${ }^{1} \mathrm{H}$ 1D-TOCSY, via selective irradiation of peaks at $6.19 \mathrm{ppm}$ and $5.12 \mathrm{ppm}$ that appeared following incubation with FgrAAO, indicated oxidation and hydration of the C- 6 hydroxyl groups of both galactose and fructose C6, respectively (full assignments of the proton and carbon spectra, for raffinose and the oxidation product using $1 \mathrm{D}\left({ }^{1} \mathrm{H},{ }^{13} \mathrm{C}\left\{{ }^{1} \mathrm{H}\right\}\right.$, TOCSY $)$ and $2 \mathrm{D}$ (HSQC, HMBC and TOCSY) NMR, Additional file 1: 


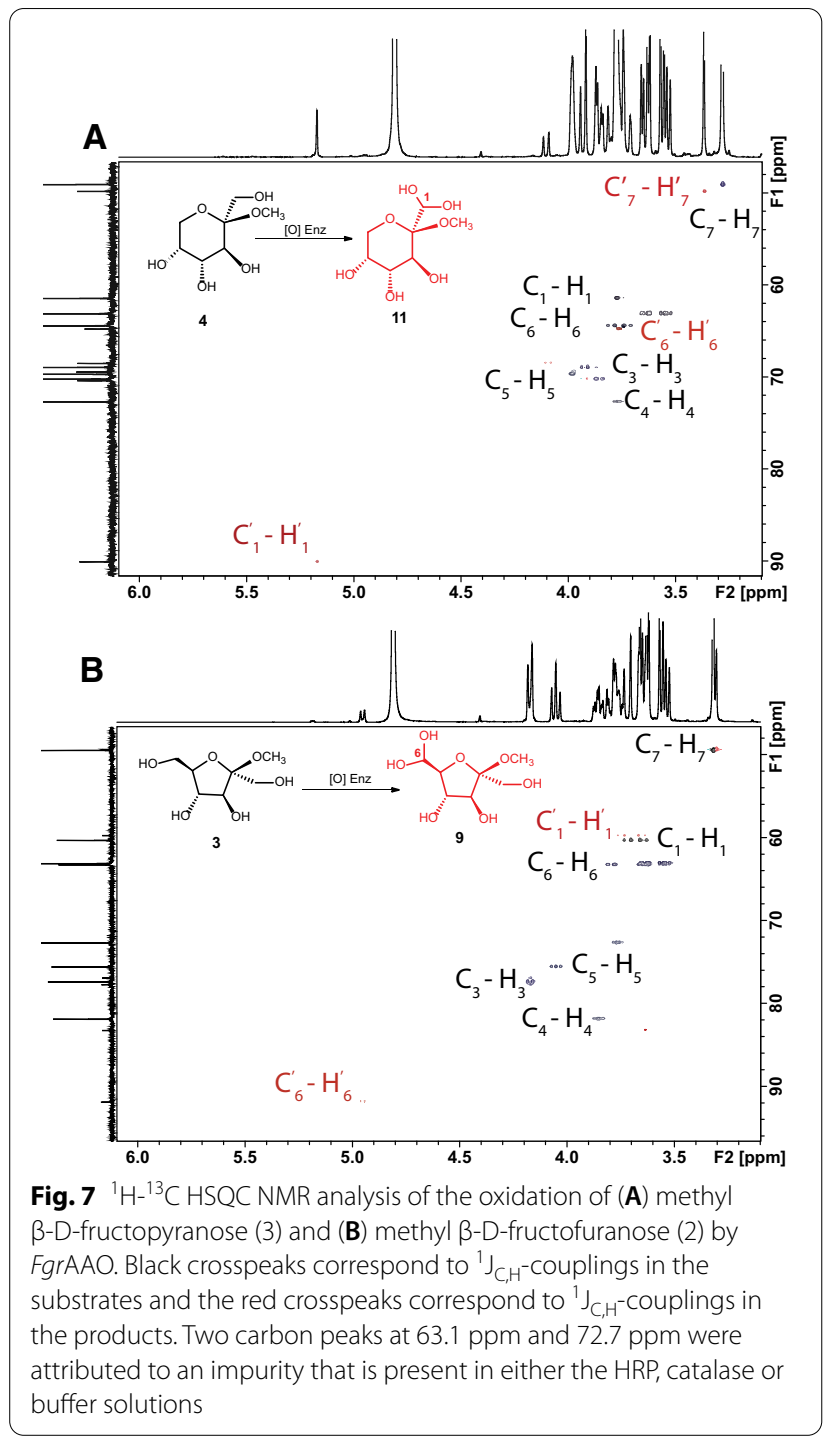

Figures S19-S22, are provided in Table S8). Specifically, no peaks corresponding to oxidation of $\mathrm{C} 1$ on the fructosyl residue were observed. Based on the NMR analysis, $87 \%$ of unoxidized raffinose remained after incubation with FgrAAO. Multiple products, including two mono-oxidized species and di-oxidized species (10), could be present, but due to low conversion no quantitative data could be obtained. The observation of the oxidation of both terminal primary hydroxyl groups in raffinose (Fig. 6) by FgrAAO is consistent with the similar $k_{\text {cat }} / K_{\mathrm{M}}$ values for the component monosaccharides, galactose and fructose. It would also appear that oxidation of $\mathrm{C} 1$ of the fructofuranosyl residue of raffinose is precluded sterically. The bis-oxidation of raffinose by FgrAAO suggests a potential route to valorize raffinose as a chemical building-block, as has previously been explored with lactose and FgrGalOx [33].
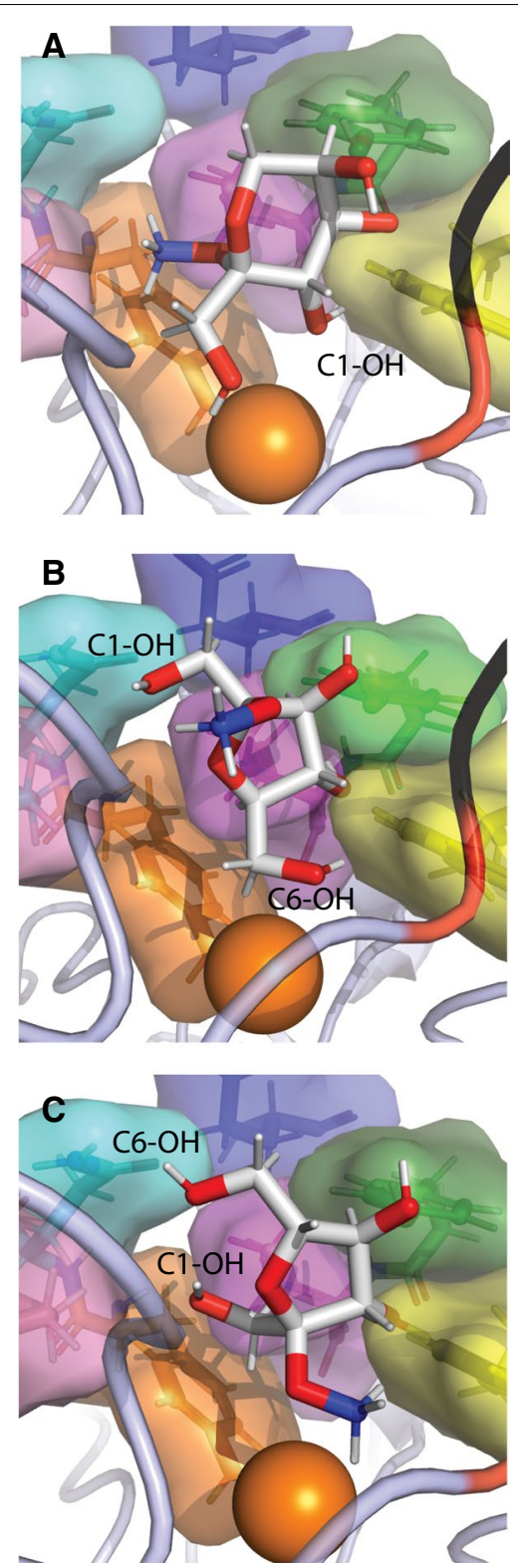

Fig. 8 Molecular docking (AutoDock Vina as implemented in Chimera) of (A) methyl $\beta$-D-fructopyranoside (3), (B) methyl $\beta$-D-fructofuranoside (2) and (C) methyl a-D-fructofuranoside (1) in FgrAAO. Copper (dark orange), methoxy group on sugar (dark blue), W290 (yellow), Y329 (green), K330 (magenta), E326 (blue), Y405 (orange), Q406 (cyan), P463 (pink), F194 (red), Q195 (black). C1-OH and $\mathrm{C} 6-\mathrm{OH}$ of each sugar are labeled

\section{Glycerol oxidation}

Glycerol is a prochiral compound that is produced in significant quantities annually, including as a byproduct of the biodiesel industry [84]. Hence, there is significant interest in the valorization of glycerol by desymmetrization. It has been previously reported that the wildtype $F g r G a l O x$ oxidizes glycerol stereoselectively to 
L-glyceraldehyde [85]. Moreover, $\mathrm{FgrGalOx}$ variants have been integral to the desymmetrization of a key 2-alkynylglycerol derivative in the synthesis of a key antiviral drug [50]. On the other hand, we have also recently shown that CgrAlcOx favors oxidation of glycerol to D-glyceraldehyde [86].

Here, comparative analysis indicates that FgrAAO and FoxAAO both oxidize glycerol predominantly to produce L-glyceraldehyde, with enantiomeric ratios $(e r)$ of 93:7 and 91:9 (L-:D-), respectively (Additional file 1: Figures S23-S24). Under similar conditions, FgrGalOx likewise favored the L-isomer, as expected, with an er of 96:4 (L-:D-), whereas the er for CgrAlcOx was 10:90 (L-:D). The similar stereoselectivities of the Fusarium AA5 CROs may be understood in terms of their conserved active-site motifs (Fig. 2). Nonetheless, the ability of these enzymes to selectively produce the unnatural and more valuable L-isomer may find biotechnological application. In this context, we note that FrrGalOx is ca. twofold more active than FgrAAO and FoxAAO.

\section{Conclusion}

In summary, a detailed biochemical characterization of two orthologous CROs from Fusarium graminearum and Fusarium oxysporum, which segregate into a previously uncharacterized clade with AA5_2, revealed a distinct substrate specificity profile versus known GalOx $[17,25$, 53-56], AlcOx [18, 26], and AAO [19] within the family. Despite strong conservation of active-site architecture compared to the archetypal FgrGalOx, both FgrAAO and FoxAAO have a novel native preference for mannose and fructose over galactose or galactosides, and a clear preference for aryl alcohols, specifically 3-methoxybenzyl alcohol and veratryl alcohol. Unlike CgrAlcOx [18], FgrAAO and FoxAAO are poorly active on unactivated alkanols, with the exception of the aforementioned saccharides and glycerol. While the nomenclature of oxidases is fraught with difficulty due to overlapping definitions of EC 1.1.3.7 (aryl alcohol oxidase), EC 1.1.3.13 (alcohol oxidase), and EC 1.1.3.47 (5-(hydroxymethyl) furfural oxidase), detailed kinetic data (Table 1 and Fig. 3) support denoting these $F$. graminearum and $F$. oxysporum CROs as aryl alcohol oxidases. High $K_{\mathrm{M}}$ values and low specificity constants $\left(k_{\mathrm{cat}} / K_{\mathrm{M}}\right.$ values $)$ do not suggest that galactose 6-oxidation (EC 1.1.3.9) is the natural activity of these enzymes. Finally, we note that the physiological substrate of these enzymes is currently unknown and may not be represented in our panel of compounds.

In this context, it is notable that FgrAAO and FoxAAO group together with orthologs from $F$. verticillioides and $F$. subglutinans in a clade previously designated as "gaoB" (galactose oxidase B) [17] (Fig. 1). However, the $F$. verticillioides and F. subglutinans gene products have not been biochemically characterized [59]. Our kinetic data on FgrAAO and FoxAAO, like data on the Colletotrichum homologs $[18,19,26]$, indicate that caution is warranted in extending functional predictions in AA5_2 on the basis of bioinformatics alone. Indeed, our analysis would suggest that the F. verticillioides and F. subglutinans orthologs are likely to also be predominant aryl alcohol oxidases. Within this clade, an arginine to lysine substitution in the active site may be a key specificity determinant.

Finally, the ability of FrrAAO and FoxAAO to oxidize HMF and derivatives, as well as glycerol, suggests possible applications of these CROs in biocatalysis. Like FADdependent oxidases, CROs use molecular oxygen as a co-substrate, thus avoiding the requirement for co-factor regeneration of NAD-dependent oxidases. At the same time, the facile production of AA5 CROs in P. pastoris and $E$. coli enables further tuning of specificity for biocatalytic applications [42, 49, 50,64], which will be further informed by enzyme structure-function relationships, including those described here. Indeed, the replacement of chemical oxidants with potentially greener biocatalysts is a topic of considerable contemporary interest.

\section{Methods}

\section{Chemicals and enzymes}

Wild-type galactose oxidase from Fusarium graminearum and alcohol oxidase from Colletotrichum graminicola were produced in Pichia pastoris and purified as previously described [18, 64]. Ultrapure water was used for the preparation of all buffers and stock solutions unless stated otherwise. Catalase from bovine liver (2000-5000 units per mg protein, Sigma) and horseradish per-oxidase $(R \mathrm{z}>3300$ units per $\mathrm{mg}$, Bio Basic Canada Inc.), obtained as lyophilized powders, were used as received. Other substrates and reagents were purchased from commercial sources (Sigma-Aldrich, VWR or Fisher) and used without further purification.

\section{Sequence and bioinformatic analysis}

Sequences of FgrAAO (GenBank XP_011322138) and FoxAAO (GenBank XP_018246910) were taken from the National Center for Biotechnology Information (NCBI). Percent identity analysis was performed using the full-length sequences of FrrAAO, FoxAAO and other AA5_2 members from the Fusarium and Colletotrichum genus using MatGat [87]. An alignment using the online Genome Net CLUSTALW tool was performed with the two new enzymes presented in this study and compared to the characterized galactose oxidase from Fusarium graminearum (FgrGalOx) (GenBank: P0CS93.1), alcohol oxidase (CgrAlcOx) (GenBank: EFQ30446.1) and aryl oxidase (CgrAAO) (GenBank: EFQ27661.1) from 
Colletotrichum graminicola. In addition, Phyre2 [88] was used to make three-dimensional homology models for FgrAAO and FoxAAO. The structural models were aligned to the crystal structures of $F g r G a l O x$ (PDBID 1GOF) [17] and CgrAlcOx (PDBIID 5C86) [18] for spatial amino acid comparison to give further support to the alignment.

In addition, two AA5_1 sequences and 62 sequences of AA5_2 members from a variety of fungal species were extracted from the public CAZY database [13] (February 2021) and aligned using MUSCLE [89]. Where present, signal sequences and additional domains, such as carbohydrate-binding modules, were removed. Any redundant sequences were excluded and the resulting catalytic domain sequences were realigned. A maximum-likelihood phylogenetic tree was estimated by RAxML version 8.2.12 [90] using 47 sequences as inputs on the CIPRES gateway [91] with automatic bootstrapping terminating at 650 bootstrap replicates. The resulting phylogeny was visualized with FigTree (http://tree.bio.ed.ac.uk/softw are/figtree/).

\section{DNA cloning}

cDNA encoding FgrAAO (GenBank ID XP_011322138) and FoxAAO (GenBank ID XP_018246910) without the predicted native signal peptide and including a C-terminal His6 tag-encoding sequence were commercially synthesized in a codon-optimized form. The sequences were cloned into the $P$. pastoris expression vector pPICZ $\alpha-\mathrm{A}$ using the EcoRI and $X b a \mathrm{I}$ restriction sites flush with the sequence encoding the $S$. cerevisiae $\alpha$-factor signal peptide by Genescipt. The resulting constructs were transformed into chemically competent $E$. coli $\mathrm{DH} 5 \alpha$ by heat shock.

In both cases, transformants were grown overnight at $37{ }^{\circ} \mathrm{C}$ on Luria-Bertani low-salt (LBLS) agar plates and selected against $25 \mu \mathrm{g} \mathrm{mL}^{-1}$ Zeocin (Invitrogen). Surviving colonies were picked and grown overnight at $37^{\circ} \mathrm{C}$ in $5 \mathrm{~mL}$ LBLS medium with $25 \mu \mathrm{g} \mathrm{mL} \mathrm{m}^{-1}$ Zeocin. Plasmids from the overnight cultures were extracted using a commercial mini-prep kit (Geneaid, New Taipei City, Taiwan). The presence of the pPICZ $\alpha-\mathrm{A}-F g r A A O$ and pPICZ $\alpha$-A-FoxAAO constructs in positive clones was checked by agarose $(1 \%$; w/v) gel electrophoresis and the correct insertion of both genes into the corresponding vectors was verified by DNA sequencing. Transformation of constructs into P. pastoris X33 was performed by digesting $6.5-14 \mu \mathrm{g}$ of plasmid DNA for $4 \mathrm{~h}$ at $37^{\circ} \mathrm{C}$ with PmeI (New England Biolabs). The linearized plasmid was purified using an ion exchange column (Omega). The resulting digested plasmids were transformed into electrocompetent $P$. pastoris X33 cells prepared on the same day [92].
Transformants were grown on yeast extract peptone dextrose (YPDS) agar plates for 2 days at $30{ }^{\circ} \mathrm{C}$ and selected against 100 or $500 \mu \mathrm{g} \mathrm{mL}^{-1}$ Zeocin. Four colonies selected from $500 \mu \mathrm{g} \mathrm{mL}{ }^{-1}$ Zeocin plates were inoculated into $15 \mathrm{~mL}$ sterile conical tubes containing $2 \mathrm{~mL}$ of YPD and grown for $6 \mathrm{~h}$ at $30{ }^{\circ} \mathrm{C}$ shaking at $200 \mathrm{rpm}$. At $\mathrm{OD} \sim 0.15,200 \mu \mathrm{L}$ of the growing culture was transferred to $10 \mathrm{~mL}$ of buffered complex glycerol medium (BMGY) and grown in a shaking incubator overnight at $30{ }^{\circ} \mathrm{C}$ and $200 \mathrm{rpm}$. Cells were then pelleted by centrifugation at $3000 \mathrm{~g}$ for $10 \mathrm{~min}$ at $25^{\circ} \mathrm{C}$, the BMGY medium was discarded and replaced with $4 \mathrm{~mL}$ of buffered complex methanol medium (BMMY) containing $0.5 \%(\mathrm{v} / \mathrm{v})$ methanol. The cultures were shaken at $200 \mathrm{rpm}$ over 3 days at either 25 or $16{ }^{\circ} \mathrm{C}$ with regular feeding of $0.5 \%$ methanol every $24 \mathrm{~h}$ to ensure continued protein expression. Secreted proteins were separated from the cells by centrifugation at $4000 \mathrm{rpm}$ for $10 \mathrm{~min}$ and protein production was monitored using SDS-PAGE. The clone yielding the highest amount of protein was retained for large-scale production.

\section{Large-scale protein production}

Single colonies of $P$. pastoris X33 expressing clones were individually streaked onto agar plates containing $500 \mu \mathrm{g}$ $\mathrm{mL}^{-1} \mu$ of the antibiotic Zeocin and grown for 2 days in the dark in a $30{ }^{\circ} \mathrm{C}$ incubator. Precultures containing $4 \mathrm{~mL}$ of YPD and $500 \mu \mathrm{g} \mathrm{mL}^{-1}$ Zeocin were inoculated using a single colony and shaken at $30{ }^{\circ} \mathrm{C}$ at $250 \mathrm{rpm}$ for $10 \mathrm{~h}$. Biomass production was initiated by the addition of the preculture into $1 \mathrm{~L}$ of BMGY media shaken in 4 $\mathrm{L}$ beveled flasks at $30^{\circ} \mathrm{C}$ at $250 \mathrm{rpm}$ overnight. Once the BMGY cultures reached an $\mathrm{OD}_{600}$ of 6-12, the cells were harvested by centrifugation at $3000 \mathrm{~g}$ for $15 \mathrm{~min}$ at room temperature. The cells were then resuspended using $400 \mathrm{~mL}$ of BMMY media supplemented with $0.5 \mathrm{mM}$ copper sulfate containing 3\% methanol and transferred to $1 \mathrm{~L}$ flasks with a foam cap. The flasks were shaken at $250 \mathrm{rpm}$ at $16{ }^{\circ} \mathrm{C}$ for three days. The cultures were fed $1 \%$ (v/v) methanol every $24 \mathrm{~h}$ to maintain continued expression of the recombinant protein. On the last day of methanol induction, the desired proteins were separated from the cells by centrifugation at $3000 \mathrm{~g}$ for $30 \mathrm{~min}$ at $4{ }^{\circ} \mathrm{C}$. The supernatant was quickly decanted, filtered through $0.45 \mu \mathrm{m}$ membrane and stored at $4{ }^{\circ} \mathrm{C}$ until purification.

\section{Protein purification}

The $\mathrm{pH}$ of the liquid medium which contained FgrAAO or FoxAAO was raised before purification to 7.5-8.0 by the dropwise addition of $1 \mathrm{M} \mathrm{NaOH}$ with stirring. The medium was the filtered through a $0.45 \mu \mathrm{m}$ membrane and allowed to equilibrate for at least $12 \mathrm{~h}$ at $4{ }^{\circ} \mathrm{C}$. The supernatant was allowed to pass through a 
$5 \mathrm{~mL}$ pre-packed Ni-NTA column, pre-equilibrated with $50 \mathrm{mM}$ sodium phosphate buffer at $\mathrm{pH} 7.5$ with $300 \mathrm{mM} \mathrm{NaCl}$ with $10 \mathrm{mM}$ imidazole at $5 \mathrm{~mL} / \mathrm{min}$. The column was washed with 5 column volumes of equilibration buffer containing $50 \mathrm{mM}$ sodium phosphate buffer at $\mathrm{pH} 7.5$ with $300 \mathrm{mM} \mathrm{NaCl}$ and $10 \mathrm{mM}$ imidazole at $4.5 \mathrm{~mL} / \mathrm{min}$. Proteins were eluted with a linear gradient of $2 \%$ to $100 \%$ of $500 \mathrm{mM}$ imidazole in a $50 \mathrm{mM}$ sodium phosphate buffer with $300 \mathrm{mM} \mathrm{NaCl}$ at $5 \mathrm{~mL} / \mathrm{min}$. The total elution volume was $125 \mathrm{~mL}$ collected in $1 \mathrm{~mL}$ fractions. Both FgrAAO and FoxAAO eluted at $140 \mathrm{mM}$ imidazole. The proteins were then concentrated using a 30,000 MWCO Vivaspin centrifugal concentrator and 0.5-1 mL was loaded onto a Superdex 75 size-exclusion column pre-equilibrated with $50 \mathrm{mM}$ sodium phosphate buffer at pH 7.5 at $1 \mathrm{~mL} / \mathrm{min}$. A total volume of $200 \mathrm{~mL}$ of equilibration buffer was used through the column at $1 \mathrm{~mL} / \mathrm{min}$. FoxAAO eluted at $102 \mathrm{~mL}$ as one singular peak, while FgrAAO eluted as two peaks at 72 and $104 \mathrm{~mL}$. SDS-PAGE was performed using pre-cast 4-20\% $(\mathrm{w} / \mathrm{v})$ polyacrylamide gel in the presence of $2 \%(\mathrm{w} / \mathrm{v})$ SDS under reducing conditions. Proteins were visualized using Coomassie blue R-250. Protein concentrations were determined by measuring $A_{280}$. The extinction coefficients were calculated using the ProtParam tool on the ExPASy server.

\section{Analytical protein deglycosylation}

The presence of protein glycosylation on FgrAAO and FoxAAO was assessed by treatment with $\mathrm{N}$-glycosidase $\mathrm{F}$ from Flavobacterium meningosepticum (PNGaseF, New England Biolabs). Deglycosylation experiments were performed under denaturing condition by adding $3 \mu \mathrm{g}$ of protein to 10X Glycoprotein Denaturing Buffer and heated for $10 \mathrm{~min}$ at $100{ }^{\circ} \mathrm{C}$. The samples were subsequently diluted to $20 \mu \mathrm{L}$ with GlycoBuffer 2 and tertigol-type NP-400 detergent. Finally, $1 \mu \mathrm{L}$ of PNGaseF was added to the sample and incubated for $1 \mathrm{~h}$ at $37^{\circ} \mathrm{C}$. Changes in protein mobility was assessed by SDS-PAGE stained with Coomassie blue R-250.

\section{$\mathrm{pH}$ and temperature profile}

Enzyme activity across a wide range of $\mathrm{pH}$ values was determined using phosphate citrate $(\mathrm{pH} 4.0-7.0)$, sodium phosphate $(\mathrm{pH} 5.5-8.5)$ and glycine- $\mathrm{NaOH}(\mathrm{pH} 8.5-$ 11.0) buffers. Enzyme activity was measured using the HRP-2,2'-azinobis(3-ethylbenzthiazoline-6-sulfonic acid) (ABTS)-coupled assay with $300 \mathrm{mM}$ of galactose at $25{ }^{\circ} \mathrm{C}$ [64]. The optimum temperature was determined using the same coupled assay using $50 \mathrm{mM}$ sodium phosphate buffer at $\mathrm{pH} 7.5$ with $1 \mu \mathrm{g} \mathrm{mL}^{-1}$ as the final enzyme concentration and $300 \mathrm{mM}$ galactose as the substrate at temperatures ranging from $15^{\circ} \mathrm{C}$ to $80^{\circ} \mathrm{C}$.

\section{Temperature stability}

Temperature stability of both FgrAAO and FoxAAO was determined by diluting the stock protein in $50 \mathrm{mM}$ sodium phosphate buffer at $\mathrm{pH} 7.5$ to obtain a final protein concentration of $0.2 \mathrm{mg} \mathrm{mL} \mathrm{m}^{-1}$ for both proteins studied. The diluted protein was then pre-incubated in a thermocycler at $30{ }^{\circ} \mathrm{C}, 39{ }^{\circ} \mathrm{C}, 49^{\circ} \mathrm{C}$ and $60{ }^{\circ} \mathrm{C}$. Samples were taken out at different time interval and the activity of the proteins was measured using the HRP-ABTS coupled assay [64] with $300 \mathrm{mM}$ galactose as the substrate at $30{ }^{\circ} \mathrm{C} .1 \mu \mathrm{g} \mathrm{mL}{ }^{-1}$ was the final enzyme concentration in the reactions.

\section{Enzyme kinetics}

The colorimetric HRP-ABTS coupled assay was used to determine the kinetics of the enzymatic oxidation of substrates. The oxidation of the alcohol group on the substrates by AA 5 enzymes consumes 1 equivalent of $\mathrm{O}_{2}$ and produces 1 equivalent of $\mathrm{H}_{2} \mathrm{O}_{2}$. The oxidation of ABTS $\left(\lambda_{\max }=420 \mathrm{~nm}, \varepsilon=36,000 \mathrm{M}^{-1} \mathrm{~cm}^{-1}\right.$ ) is catalyzed by the enzymes HRP using 2 equivalents of $\mathrm{H}_{2} \mathrm{O}_{2}$ [64]. This assay was optimized for sensitivity and linearity.

The activity of FgrAAO and FoxAAO was surveyed on a variety of substrates using this coupled assay comprising $50 \mathrm{mM}$ sodium phosphate buffer at $\mathrm{pH} 7.5,0.46 \mathrm{mM}$ ABTS and $30 \mathrm{U} / \mathrm{mL}$ of $\mathrm{HRP}$ at $25{ }^{\circ} \mathrm{C}$. The initial substrate screen included carbohydrates, polyols, diols and primary alcohol substrates at $300 \mathrm{mM}$, polysaccharides at $2.5 \mathrm{mg} \mathrm{mL}^{-1}$, benzyl alcohol and galactitol at $30 \mathrm{mM}$, methyl glyoxal, aryl alcohols and furans at $5 \mathrm{mM}$ and $10 \mathrm{mM}$ for secondary alcohols. One unit of AA5 enzyme activity was defined as the amount of enzyme required to oxidize $2 \mu \mathrm{mol}$ of ABTS per minute, which is equivalent to the consumption of $1 \mu \mathrm{mol}$ of oxygen per minute.

To determine Michaelis-Menten parameters of FgrAAO and FoxAAO, different concentrations of substrates were used over the range of $10-2500 \mathrm{mM}$ for galactose, $10-4000 \mathrm{mM}$ for fructose, $5-3000 \mathrm{mM}$ for mannose, 25-7000 mM for glycerol, $10-250 \mathrm{mM}$ for benzyl alcohol, 0.5-13 mM for cinnamyl alcohol, 1-200 mM for $p$-anisyl alcohol for FgrAAO and 1-100 mM for FoxAAO, $0.25-100 \mathrm{mM}$ for $m$-anisyl alcohol for FgrAAO and $0.25-50 \mathrm{mM}$ for FoxAAO, 0.25-10 mM for veratryl alcohol, 1-80 mM for HMF, $0.25-20 \mathrm{mM}$ for HMFCA and $0.1-40 \mathrm{mM}$ for DFF for FrrAAO and $0.5-20 \mathrm{mM}$ for FoxAAO. The reactions were performed at $35^{\circ} \mathrm{C}$ in $50 \mathrm{mM}$ sodium phosphate buffer at $\mathrm{pH} 7.5$ with $0.46 \mathrm{mM}$ ABTS, $30 \mathrm{U} / \mathrm{mL}$ of HRP and using 2.1 to $28 \mathrm{pmol}$ of purified FgrAAO and FoxAAO. Data were fit with the Michaelis - Menten equation using OriginPro software (OriginLab 9.55). 


\section{Computational docking studies}

Molecular docking simulations were performed using the CHIMERA software from UCSF Resource for Biocomputing, Visualization, and Informatics [93]. The FgrGalOx crystal structure (PDB 1GOF) and a Phyre model of FgrAAO were used to generate the receptors for simulations. Ligands were either extracted from other PDB files or build from components extracted from other PDB files. Ligands and receptors were first prepared for docking in chimera by adding hydrogens and assigning proper protonation states. The docking simulation itself was performed using Autodock VINA, run within CHIMERA, with the AMBER03 force field [94]. Appropriate simulation cells were defined for the respective docking simulations. For docking of galactose and mannose, a $7 \AA$ cell with the copper atom bordering the $\mathrm{z}$-coordinate edge was chosen. Galactose gave a reasonable binding pose with both FgrGalOx and FgrAAO, while mannose lowest energy structures produced the sugar in unproductive binding positions. For the docking of methyl $\alpha / \beta$-fructofuranosides and methyl $\beta$-fructopyranoside, a $6 \times 7 \times 7 \AA$ cell was selected with the copper atom bordering the z-coordinate edge. Reasonable functional binding poses were calculated for methyl $\beta$-fructofuranosides and methyl $\beta$-fructopyranoside, and an unproductive for catalytic turnover binding structure was calculated for methyl $\alpha$-fructofuranosides. The created receptor-ligand complex structures were further processed using the PyMOL software from Schrodinger LLC involving the identification of ligand-receptor interaction and for the determination of distances.

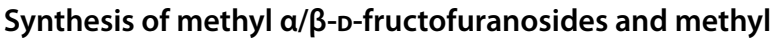 $\beta$-D-fructopyranoside}

The 1-O-methyl D-fructose derivatives were prepared according to a modified procedure [82]. To a solution of D-fructose $(1.00 \mathrm{~g}, 0.111 \mathrm{~mol})$ in $\mathrm{MeOH}(50 \mathrm{~mL}) 50 \mu \mathrm{l}$ of acetyl chloride $(\mathrm{AcCl})$ was added at RT and stirred for $25 \mathrm{~h}$. The reaction was neutralized with Dowex 66 Free Base resin, filtered, washed with $\mathrm{MeOH}$ and concentrated. Half the crude mixture was purified by anion exchange chromatography (Dowex $1 \times 8$ 200-400, ${ }^{-} \mathrm{OH}$ form; distilled water as the mobile phase), which yielded three products: methyl $\alpha$-D-fructofuranoside (0.193 g, $39 \%, \mathrm{R}_{\mathrm{f}} 0.58$ [6:4:1, EtOAc- $\left.i-\mathrm{PrOH}-\mathrm{H}_{2} \mathrm{O}\right]$ ), methyl $\beta-\mathrm{D}-$ fructofuranoside $\left(0.064 \mathrm{~g}, 13 \%, \mathrm{R}_{\mathrm{f}} 0.46\right)$, methyl $\beta-\mathrm{D}-$ fructopyranoside $\left(0.084 \mathrm{~g}, 17 \%, \mathrm{R}_{\mathrm{f}} 0.34\right)$ and a mixture of methyl $\alpha / \beta$-D-fructofuranoside $(0.004 \mathrm{~g}, 0.8 \%)$ and methyl $\quad \beta$-D-fructofuranoside/ $\beta$-D-fructopyranoside $(0.141 \mathrm{~g}, 29 \%)$ all as clear gels, giving a total purification yield of $99 \%$.
Methyl $\alpha$-D-fructofuranoside: ${ }^{1} \mathrm{H}$ NMR $(400 \mathrm{MHz}$, $\left.\mathrm{D}_{2} \mathrm{O}\right): \delta=3.22\left(\mathrm{~s}, 3 \mathrm{H}, \mathrm{H}_{7}\right), 3.68(\mathrm{dd}, J=32.6,12.3 \mathrm{~Hz}, 4 \mathrm{H}$ overlapped with $\left.\mathrm{H}_{6}, \mathrm{H}_{1}\right), 3.72$ (m, $4 \mathrm{H}$ overlapped with $\mathrm{H}_{1}$, $\left.\mathrm{H}_{6}\right), 3.85\left(\mathrm{~m}, 1 \mathrm{H}, \mathrm{H}_{4}\right), 4.05\left(\mathrm{t}, J=7.8 \mathrm{~Hz}, 1 \mathrm{H}, \mathrm{H}_{5}\right), 4.17(\mathrm{~d}$, $\left.J=8.2 \mathrm{~Hz}, 1 \mathrm{H}, \mathrm{H}_{3}\right) .{ }^{13} \mathrm{C}\left\{{ }^{1} \mathrm{H}\right\} \operatorname{NMR}\left(100.6 \mathrm{MHz}, \mathrm{D}_{2} \mathrm{O}\right): \delta$ $49.5\left(C_{7}\right), 60.5\left(C_{1}\right), 63.3\left(C_{6}\right), 75.7\left(C_{5}\right), 77.6\left(C_{3}\right), 82.0$ $\left(\mathrm{C}_{4}\right), 104.4\left(\mathrm{C}_{2}\right)$

Methyl $\beta$-D-fructofuranoside: ${ }^{1} \mathrm{HNMR}(400 \mathrm{MHz}$, $\left.\mathrm{D}_{2} \mathrm{O}\right): \delta 3.32\left(\mathrm{~s}, 3 \mathrm{H}, \mathrm{H}_{7}\right), 3.73(\mathrm{dd}, J=49.7,12.8 \mathrm{~Hz}, 4 \mathrm{H}$ overlapped with $\mathrm{H}_{6}, \mathrm{H}_{1}$ ), 3.75 (dd, $J=52.6,12.9 \mathrm{~Hz}, 4 \mathrm{H}$ overlapped with $\left.\mathrm{H}_{1}, \mathrm{H}_{6}\right), 3.96\left(\mathrm{~m}, 2 \mathrm{H}, \mathrm{H}_{4}\right.$ and $\left.\mathrm{H}_{5}\right), 4.10$ $\left(\mathrm{m}, 1 \mathrm{H}, \mathrm{H}_{3}\right) .{ }^{13} \mathrm{C}\left\{{ }^{1} \mathrm{H}\right\}$ NMR $\left(100.6 \mathrm{MHz}, \mathrm{D}_{2} \mathrm{O}\right): \delta=48.8$ $\left(\mathrm{C}_{7}\right), 58.4\left(\mathrm{C}_{1}\right), 61.9\left(\mathrm{C}_{6}\right), 77.9\left(\mathrm{C}_{5}\right), 80.7\left(\mathrm{C}_{3}\right), 83.8\left(\mathrm{C}_{4}\right)$, $108.9\left(\mathrm{C}_{2}\right)$.

Methyl $\beta$-D-fructopyranoside: ${ }^{1} \mathrm{HNMR}(400 \mathrm{MHz}$, $\left.\mathrm{D}_{2} \mathrm{O}\right): \delta=3.29\left(\mathrm{~s}, 3 \mathrm{H}, \mathrm{H}_{7}\right), 3.76(\mathrm{dd}, J=31.4,13.0 \mathrm{~Hz}, 4 \mathrm{H}$ overlapped with $\left.\mathrm{H}_{1}, \mathrm{H}_{6}\right), 3.77$ (s, $4 \mathrm{H}$ overlapped with $\mathrm{H}_{6}$, $\left.\mathrm{H}_{1}\right), 3.85\left(\mathrm{~m}, 1 \mathrm{H}, \mathrm{H}_{4}\right), 3.92\left(\mathrm{~d}, J=10.0 \mathrm{~Hz}, 1 \mathrm{H}, \mathrm{H}_{3}\right), 3.97$ $\left(\mathrm{m}, 1 \mathrm{H}, \mathrm{H}_{5}\right) .{ }^{13} \mathrm{C}\left\{{ }^{1} \mathrm{H}\right\}$ NMR $\left(100.6 \mathrm{MHz}, \mathrm{D}_{2} \mathrm{O}\right): \delta 49.1\left(\mathrm{C}_{7}\right)$, $61.6\left(\mathrm{C}_{1}\right), 65.2\left(\mathrm{C}_{6}\right), 68.6\left(\mathrm{C}_{3}\right), 69.3\left(\mathrm{C}_{5}\right), 70.0\left(\mathrm{C}_{4}\right), 101.2$ $\left(\mathrm{C}_{2}\right)$.

\section{Enzyme product analysis Oxidation of methyl $\alpha / \beta$-D-fructofuranosides and methyl $\beta$-D-fructopyranoside}

Reactions containing $20 \mathrm{mg}$ of substrate (methyl $\alpha / \beta-\mathrm{D}$ fructofuranosides and methyl $\beta$-D-fructopyranoside) and $1 \mathrm{mg} \mathrm{mL}^{-1}$ of both catalase and HRP were initiated by the addition of $300 \mu \mathrm{g}$ of purified FgrAAO and FoxAAO in a final volume of $1 \mathrm{~mL}$ (50 mM sodium phosphate buffer, $\mathrm{pH}$ 7.5). Reactions were stirred at $400 \mathrm{rpm}$ at room temperature for $16 \mathrm{~h}$, at which time the enzymes were removed by ultrafiltration (10 kDa cut-off Centricon-Millipore, Billerica, MA, USA). The products were collected, frozen in liquid nitrogen and lyophilized for 4 days. The resulting powders were resuspended in $\mathrm{D}_{2} \mathrm{O}$ and a preliminary NMR analysis was conducted. The samples were subsequently lyophilized for $24 \mathrm{~h}$ and a second reaction was performed under the previously mentioned conditions with $500 \mu \mathrm{g}$ of purified enzyme added. The reaction was stirred for $25 \mathrm{~h}$ and the same work-up procedure was followed.

In this and subsequent product analyses, NMR spectra were acquired on a Bruker AV III HD $400 \mathrm{MHz}$ spectrometer equipped with a BBFO smart probe. ${ }^{1} \mathrm{H}$ and ${ }^{13} \mathrm{C}$ spectra were calibrated using an internal standard of acetone $(0.34 \mathrm{M} ; 2.22 \mathrm{ppm}$ and $30.89 \mathrm{ppm}$, respectively). Peak integration values were used to determine the extent of substrate conversion to product(s). 
Oxidation of 2,5-anhydromannitol and 2,5-anhydroglucitol Reactions containing $20 \mathrm{mg}$ of substrate (2,5-anhydroD-mannitol and 2,5-anhydro-D-glucitol) and $1 \mathrm{mg} \mathrm{mL}^{-1}$ of both catalase and HRP (dissolved in $\mathrm{D}_{2} \mathrm{O}$ ) were initiated by the addition of $700 \mu \mathrm{g}$ of purified FgrAAO in a final volume of $1 \mathrm{~mL}$ (50 mM sodium phosphate buffer, $\mathrm{pH} 7.5$ previously lyophilized and resuspended in $\mathrm{D}_{2} \mathrm{O}$ ). Reactions were stirred at $400 \mathrm{rpm}$ at room temperature for $24 \mathrm{~h}$, at which time the enzymes were removed by ultrafiltration (5 kDa cut-off Centricon-Millipore, Billerica, MA, USA).

\section{Oxidation of raffinose}

Reactions containing $20 \mathrm{mg}$ of raffinose and $1 \mathrm{mg} \mathrm{mL}$ of both catalase and HRP were initiated by the addition of $800 \mu \mathrm{g}$ of purified FgrAAO in a final volume of $1 \mathrm{~mL}$ (50 mM sodium phosphate buffer, $\mathrm{pH}$ 7.5). A control reaction without $F g r A A O$ was performed using the same protocol. Reactions were stirred at $400 \mathrm{rpm}$ at room temperature for $25 \mathrm{~h}$, at which time the enzymes were removed by ultrafiltration ( $5 \mathrm{kDa}$ cut-off Centricon-Millipore, Billerica, MA, USA). The products were collected, frozen in liquid nitrogen and lyophilized for 3 days. The resulting powders were resuspended in $\mathrm{D}_{2} \mathrm{O}$ for NMR analysis.

\section{Oxidation of HMF, DFF, HMFCA, FDCA and furfural}

Reactions containing $10 \mathrm{mM}$ of substrate (HMF, DFF, HMFCA, FDCA and furfural) and $1 \mathrm{mg} \mathrm{mL}^{-1}$ of both catalase and HRP were initiated by the addition of $60 \mu \mathrm{g}$ of purified FgrAAO and FoxAAO in a final volume of $1 \mathrm{~mL}$ (50 mM sodium phosphate buffer, $\mathrm{pH}$ 7.5). For each reaction a negative control was performed with identical conditions omitting the purified enzyme. Reactions were stirred at $400 \mathrm{rpm}$ at room temperature for $16.5 \mathrm{~h}$, at which time the enzymes were removed by ultrafiltration (5 kDa cut-off Centricon-Millipore, Billerica, MA, USA). $\mathrm{D}_{2} \mathrm{O}$ was added to the filtrate to a final composition of $10 \%(\mathrm{v} / \mathrm{v}) .{ }^{1} \mathrm{H}$ NMR spectra were collected with water suppression $(4.7 \mathrm{ppm})$ using a standard pre-saturation pulse sequence. Chemical shifts were calibrated to the internal HOD peak (4.7 ppm). Standards of all substrates were used to identify distinct chemical shifts for each molecule.

\section{Oxidation of glycerol}

Reaction containing $0.54 \mathrm{M}$ glycerol and $1 \mathrm{mg} \mathrm{mL}^{-1}$ of both catalase and HRP were initiated by the addition of $800 \mu \mathrm{g}$ of purified $\mathrm{FgrGalOx}, \mathrm{CgrAlcOx}, \mathrm{FgrAAO}$ and FoxAAO in a final volume of $1 \mathrm{~mL}$ ( $50 \mathrm{mM}$ sodium phosphate buffer, $\mathrm{pH}$ 7.0-8.0). Reactions were left at room temperature for $24 \mathrm{~h}$, at which time the enzymes were removed by ultrafiltration ( $5 \mathrm{kDa}$ cut-off Centricon-Millipore, Billerica, MA, USA). $20 \mathrm{mg}$ of 2,4-dinitrophenyl hydrazine was added to the Eppendorf and the reaction mixture was incubated in a heat block at $50{ }^{\circ} \mathrm{C}$ for $6 \mathrm{~h}$. A TLC plate was used to check formation of desired product $\left(R_{\mathrm{f}}=0.45100 \% \mathrm{EtOAc}\right)$. Subsequently, the solution was purified via preparatory TLC and the desired hydrazone was mechanically isolated and dissolved in $\mathrm{MeOH}$. The solution was then filtered and concentrated. The composition of the purified glyceraldehyde-hydrazones was analyzed on HPLC ( $3 \mu \mathrm{L}$ injection, Chiracel ${ }^{\circledR}$ IA-3). Eluents used for HPLC methods, water with $0.1 \%$ formic acid (A) and methanol (B) were LC-MS grade (Optima, Fisher). For separation between L-and D-glyceraldehyde-hydrazones an isocratic method using $60 \% \mathrm{~A}$, $40 \%$ B with a flow rate of $0.65 \mathrm{~mL} / \mathrm{min}$ was used with a $12 \mathrm{~min}$ stop time with UV detection at $360 \mathrm{~nm}$. L-glyceraldehyde-hydrazone eluted at $2.30 \mathrm{~min}$ and D-glyceraldehyde-hydrazone eluted at $2.76 \mathrm{~min}$. ESI mass spectra were also collected in positive mode scan for $m / z$ 95-500 running at $0.8 \mathrm{~s} /$ cycle drying gas $=5.0 \mathrm{~L} / \mathrm{min}$, nebulizer pressure $=50 \mathrm{psi}$, gas temperature $=300{ }^{\circ} \mathrm{C}$, capillary voltage $=4000 \mathrm{~V}$.

\section{Supplementary Information}

The online version contains supplementary material available at https://doi. org/10.1186/s13068-021-01984-0.

Additional file 1: Supplementary Tables S1-S8 and Supplementary Figures S1-S24.

\section{Acknowledgements}

We thank Dr. Maria Ezhova and Dr. Zhicheng (Paul) Xia (UBC Department of Chemistry) for support with NMR data acquisition and Dr. Mireille Haon (INRAE-UMR 1163, Marseille) for preliminary protein production trials.

\section{Authors' contributions}

MC produced recombinant enzymes, performed all enzyme kinetic and product analysis, and drafted the manuscript. ML cloned cDNA and generated expression strains. MC and RX optimized and performed glyceraldehyde stereochemistry analysis with significant support from RC, PM, and JH. HB conceived the study, directed research, and revised the manuscript with input from all co-authors. All authors read and approved the final manuscript.

\section{Funding}

Funding is gratefully acknowledged from: The Natural Sciences and Engineering Research Council of Canada (NSERC) Discovery Grants RGPIN 435223-13 and RGPIN-2018-03892. NSERC Strategic Partnership Grant NETGP 451431-13 for the "NSERC Industrial Biocatalysis Network". NSERC Strategic Partnership Grant (STPGP 493781-16) and joint Agence Nationale de la Recherche grant (ANR-17-CE07-0047), "FUNTASTIC_-Fungal copper radical oxidases as new biocatalysts for the valorization of biomass carbohydrates and alcohols". Genome Canada/Genome BC/Ontario Genomics/Genome Quebec for the Large-Scale Applied Research Project (LSARP, project \#10405), "SYNBIOMICS—Functional genomics and techno-economic models for advanced biopolymer synthesis").

\section{Availability of data and materials}

All data generated or analyzed during this study are included in this published article and its supplementary information files. All nucleotide sequence, protein sequence, and protein structural information used in this work was 
extracted from existing accessions in public databases, e.g., GenBank and the Protein Data Bank.

\section{Declarations}

\section{Ethics approval and consent to participate}

Not applicable.

\section{Consent for publication}

Not applicable.

\section{Competing interests}

The authors declare that they have no competing interests.

\section{Author details}

${ }^{1}$ Michael Smith Laboratories, University of British Columbia, 2185 East Mall, Vancouver, BC V6T 1Z4, Canada. ${ }^{2}$ Department of Chemistry, University of British Columbia, 2036 Main Mall, Vancouver, BC V6T 1Z1, Canada. ${ }^{3}$ BioProducts Institute, University of British Columbia, 2385 East Mall, Vancouver, BC V6T 1Z4, Canada. ${ }^{4}$ Aix Marseille Univ, CNRS, Centrale Marseille, iSm2, Marseille, France. ${ }^{5}$ Department of Biochemistry and Molecular Biology, University of British Columbia, 2350 Health Sciences Mall, Vancouver, BC V6T 1Z3, Canada. ${ }^{6}$ Department of Botany, University of British Columbia, 3200 University Boulevard, Vancouver, BC V6T 1Z4, Canada.

\section{Received: 20 March 2021 Accepted: 3 June 2021}

Published online: 16 June 2021

\section{References}

1. Fabian N. Economics: Support low-carbon investment. Nature. 2015;519:27-9.

2. Tollefson J. Can the world kick its fossil-fuel addiction fast enough? Nature. 2018;7702:422-5.

3. Fatih Demirbas M. Biorefineries for biofuel upgrading: a critical review. Appl Energy. 2009;86(Supplement 1):S151-61.

4. Venkata Mohan S, Nikhil GN, Chiranjeevi P, Nagendranatha Reddy C, Rohit MV, Kumar AN, Sarkar O. Waste biorefinery models towards sustainable circular bioeconomy: critical review and future perspectives. Bioresour Technol. 2016;215:2-12.

5. Bender TA, Dabrowski JA, Gagné MR. Homogeneous catalysis for the production of low-volume, high-value chemicals from biomass. Nat Rev Chem. 2018;2(5):35-46.

6. Goswami P, Chinnadayyala SSR, Chakraborty M, Kumar AK, Kakoti A. An overview on alcohol oxidases and their potential applications. Appl Microbiol Biotechnol. 2013;97(10):4259-75.

7. Hollmann F, Arends IWCE, Buehler K, Schallmey A, Bühler B. Enzymemediated oxidations for the chemist. Green Chem. 2011;13(2):226-65.

8. Hernández-Ortega A, Ferreira P, Martínez AT. Fungal aryl-alcohol oxidase: a peroxide-producing flavoenzyme involved in lignin degradation. Appl Microbiol Biotechnol. 2012;93(4):1395-410.

9. Srivastava N, Srivastava M, Mishra PK, Gupta VK, Molina G, RodriguezCouto S, Manikanta A, Ramteke PW. Applications of fungal cellulases in biofuel production: advances and limitations. Renew Sustain Energy Rev. 2018;82:2379-86.

10. Payne CM, Knott BC, Mayes HB, Hansson H, Himmel ME, Sandgren M, Ståhlberg J, Beckham GT. Fungal cellulases. Chem Rev. 2015;115(3):1308-448.

11. Knob A, Terrasan CRF, Carmona EC. $\beta$-Xylosidases from filamentous fungi: an overview. World J Microbiol Biotechnol. 2010;26(3):389-407.

12. Juturu V, Wu JC. Microbial xylanases: engineering, production and industrial applications. Biotechnol Adv. 2012;30(6):1219-27.

13. Levasseur A, Drula E, Lombard V, Coutinho PM, Henrissat B. Expansion of the enzymatic repertoire of the CAZy database to integrate auxiliary redox enzymes. Biotechnol Biofuels. 2013;6(1):41

14. Liese A, Seelbach K, Wandrey C. Industrial Biotransformations. 2nd ed. Weinheim: Wiley-VCH; 2006
15. Kersten P, Cullen D. Copper radical oxidases and related extracellular oxidoreductases of wood-decay Agaricomycetes. Fungal Genet Biol. 2014:72:124-30.

16. Turner NJ. 7.12 Oxidation: oxidases. In: Carreira EM, Yamamoto H, editors. Comprehensive chirality. Amsterdam: Elsevier; 2012. p. 256-74.

17. Ito N, Phillips SEV, Yadav KDS, Knowles PF. Crystal structure of a free radical enzyme, Galactose Oxidase. J Mol Biol. 1994;238(5):794-814.

18. Yin $D$, Urresti S, Lafond M, Johnston EM, Derikvand F, Ciano L, Berrin J-G, Henrissat B, Walton PH, Davies GJ, Brumer H. Structure-function characterization reveals new catalytic diversity in the galactose oxidase and glyoxal oxidase family. Nat Commun. 2015;6(1):10197.

19. Mathieu Y, Offen WA, Forget SM, Ciano L, Viborg AH, Blagova E, Henrissat B, Walton PH, Davies GJ, Brumer H. Discovery of a fungal copper radical oxidase with high catalytic efficiency toward 5-hydroxymethylfurfural and benzyl alcohols for bioprocessing. ACS Catal. 2020;10(5):3042-58.

20. Whittaker MM, Kersten PJ, Nakamura N, Sanders-Loehr J, Schweizer ES, Whittaker JW. Glyoxal oxidase from Phanerochaete chrysosporium is a new radical-copper oxidase. J Biol Chem. 1996;271(2):681-7.

21. Avigad G, Amaral D, Asensio C, Horecker BL. The d-galactose oxidase of Polyporus circinatus. J Biol Chem. 1962;237(9):2736-43.

22. Cooper JAD, Smith W, Bacila M, Medina H. Galactose oxidase from Polyporus circinatus, Fr. J Biol Chem. 1959;234(3):445-8.

23. Nobles MK, Madhosingh C. Dactylium dendroides (Bull.) Fr. Misnamed as Polyporuscircinatus Fr. Biochem Biophys Res Commun. 1963;12(2):146-7.

24. Ögel ZB, Brayford D, McPherson MJ. Cellulose-triggered sporulation in the galactose oxidase-producing fungus Cladobotryum (Dactylium) dendroides NRRL 2903 and its re-identification as a species of Fusarium. Mycol Res. 1994;98(4):474-80.

25. Whittaker JW. Free radical catalysis by galactose oxidase. Chem Rev 2003;103(6):2347-64.

26. Oide S, Tanaka Y, Watanabe A, Inui M. Carbohydrate-binding property of a cell wall integrity and stress response component (WSC) domain of an alcohol oxidase from the rice blast pathogen Pyricularia oryzae. Enzyme Microb Technol. 2019;125:13-20.

27. Leuthner $B$, Aichinger $C$, Oehmen E, Koopmann E, Müller $O$, Müller $P$, Kahmann R, Bölker M, Schreier P. A $\mathrm{H}_{2} \mathrm{O}_{2}$-producing glyoxal oxidase is required for filamentous growth and pathogenicity in Ustilago maydis. Mol Genet Genomics. 2005;272(6):639-50.

28. Roberts GP, Gupta SK. Use of galactose oxidase in the histochemical examination of mucus-secreting cells. Nature. 1965;207(4995):425-6.

29. Heitzmann H, Richards FM. Use of the avidin-biotin complex for specific staining of biological membranes in electron microscopy. Proc Natl Acad Sci U S A. 1974;71(9):3537-41.

30. Wilchek M, Spiegel S, Spiegel Y. Fluorescent reagents for the labeling of glycoconjugates in solution and on cell surfaces. Biochem Biophys Res Commun. 1980;92(4):1215-22.

31. Ramya TNC, Weerapana E, Cravatt BF, Paulson JC. Glycoproteomics enabled by tagging sialic acid- or galactose-terminated glycans. Glycobiology. 2012;23(2):211-21.

32. Monosik R, Stredansky M, Tkac J, Sturdik E. Application of enzyme biosensors in analysis of food and beverages. Food Anal Methods. 2012;5(1):40-53.

33. Schoevaart R, Kieboom T. Application of galactose oxidase in chemoenzymatic one-pot cascade reactions without intermediate recovery steps. Top Catal. 2004;27(1):3-9.

34. Mikkonen KS, Parikka K, Suuronen J-P, Ghafar A, Serimaa R, Tenkanen M. Enzymatic oxidation as a potential new route to produce polysaccharide aerogels. RSC Adv. 2014;4(23):11884-92.

35. Leppänen A-S, Xu C, Parikka K, Eklund P, Sjöholm R, Brumer H, Tenkanen M, Willför S. Targeted allylation and propargylation of galactose-containing polysaccharides in water. Carbohydr Polym. 2014;100:46-54.

36. Xu C, Spadiut O, Araújo AC, Nakhai A, Brumer H. Chemo-enzymatic assembly of clickable cellulose surfaces via multivalent polysaccharides. ChemSusChem. 2012;5(4):661-5.

37. Yalpani M, Hall LD. Some chemical and analytical aspects of polysaccharide modifications II. A high-yielding, specific method for the chemical derivatization of galactose-containing polysaccharides: oxidation with galactose oxidase followed by reductive amination. J Polym Sci, Polym Chem Ed. 1982;20(12):3399-420.

38. Kelleher FM, Bhavanandan VP. Preparation and characterization of beta-D-fructofuranosyl O-(alpha-D-galactopyranosyl uronic 
acid)-(1-6)-O-alpha-D-glucopyranoside and O-(alpha-D-galactopyranosyl uronic acid)-(1-6)-D-glucose. Carbohydr Res. 1986;155:89-97.

39. Sun L, Bulter T, Alcalde M, Petrounia IP, Arnold FH. Modification of galactose oxidase to introduce glucose 6-oxidase activity. ChemBioChem. 2002;3(8):781-3.

40. Lippow SM, Moon TS, Basu S, Yoon SH, Li X, Chapman BA, Robison K, Lipovšek D, Prather KL. Engineering enzyme specificity using computational design of a defined-sequence library. Chem Biol. 2010;17(12):1306-15.

41. Deacon SE, Mahmoud K, Spooner RK, Firbank SJ, Knowles PF, Phillips SEV, McPherson MJ. Enhanced fructose oxidase activity in a galactose oxidase variant. ChemBioChem. 2004;5(7):972-9.

42. Rannes JB, loannou A, Willies SC, Grogan G, Behrens C, Flitsch SL, Turner NJ. Glycoprotein labeling using engineered variants of galactose oxidase obtained by directed evolution. J Am Chem Soc. 2011;133(22):8436-9.

43. Escalettes F, Turner NJ. Directed evolution of galactose oxidase: generation of enantioselective secondary alcohol oxidases. ChemBioChem. 2008:9(6):857-60

44. Herter S, McKenna SM, Frazer AR, Leimkuhler S, Carnell AJ, Turner NJ. Galactose oxidase variants for the oxidation of amino alcohols in enzyme cascade synthesis. ChemCatChem. 2015;7(15):2313-7.

45. Birmingham WR, Turner NJ. A single enzyme oxidative "cascade" via a dual-functional galactose oxidase. ACS Catal. 2018;8(5):4025-32.

46. Delagrave S, Murphy DJ, Pruss JLR, Maffia AM III, Marrs BL, Bylina EJ, Coleman WJ, Grek CL, Dilworth MR, Yang MM, Youvan DC. Application of a very high-throughput digital imaging screen to evolve the enzyme galactose oxidase. Protein Eng Des Sel. 2001;14(4):261-7.

47. Wilkinson D, Akumanyi $N$, Hurtado-Guerrero R, Dawkes $H$, Knowles PF, Phillips SEV, McPherson MJ. Structural and kinetic studies of a series of mutants of galactose oxidase identified by directed evolution. Protein Eng Des Sel. 2004;17(2):141-8.

48. Deacon SE, McPherson MJ. Enhanced expression and purification of fungal galactose oxidase in Escherichia coli and use for analysis of a saturation mutagenesis library. ChemBioChem. 2011;12(4):593-601.

49. Sun L, Petrounia IP, Yagasaki M, Bandara G, Arnold FH. Expression and stabilization of galactose oxidase in Escherichia coli by directed evolution. Protein Eng Des Sel. 2001;14(9):699-704.

50. Huffman MA, Fryszkowska A, Alvizo O, Borra-Garske M, Campos KR, Canada KA, Devine PN, Duan D, Forstater JH, Grosser ST, Halsey HM, Hughes GJ, Jo J, Joyce LA, Kolev JN, Liang J, Maloney KM, Mann BF, Marshall NM, McLaughlin M, Moore JC, Murphy GS, Nawrat CC, Nazor J, Novick S, Patel NR, Rodriguez-Granillo A, Robaire SA, Sherer EC, Truppo MD, Whittaker AM, Verma D, Xiao L, Xu Y, Yang H. Design of an in vitro biocatalytic cascade for the manufacture of islatravir. Science. 2019;366(6470):1255-9.

51. Pickl M, Fuchs M, Glueck SM, Faber K. The substrate tolerance of alcohol oxidases. Appl Microbiol Biotechnol. 2015;99(16):6617-42.

52. Siebum A, van Wijk A, Schoevaart R, Kieboom T. Galactose oxidase and alcohol oxidase: scope and limitations for the enzymatic synthesis of aldehydes. J Mol Catal B: Enzym. 2006;41(3):141-5.

53. Paukner R, Staudigl P, Choosri W, Haltrich D, Leitner C. Expression, purification, and characterization of galactose oxidase of Fusarium sambucinum in E. coli. Protein Expression Purif. 2015;108:73-9.

54. Paukner R, Staudigl P, Choosri W, Sygmund C, Halada P, Haltrich D, Leitner C. Galactose oxidase from Fusarium oxysporum - expression in E. coli and P. pastoris and biochemical characterization. PLOS ONE. 2014;9(6):e100116.

55. Andberg M, Mollerup F, Parikka K, Koutaniemi S, Boer H, Juvonen M, Master E, Tenkanen M, Kruus K. A novel Colletotrichum graminicola raffinose oxidase in the AA5 family. Appl Environ Microbiol. 2017:83(20):e01383-e1417.

56. Faria CB, de Castro FF, Martim DB, Abe CAL, Prates KV, de Oliveira MAS, Barbosa-Tessmann IP. Production of galactose oxidase inside the Fusarium fujikuroi species complex and recombinant expression and characterization of the galactose oxidase GaoA protein from Fusarium subglutinans. Mol Biotechnol. 2019;61(9):633-49.

57. Rogers MS, Tyler EM, Akyumani N, Kurtis CR, Spooner RK, Deacon SE, Tamber S, Firbank SJ, Mahmoud K, Knowles PF, Phillips SEV, McPherson MJ, Dooley DM. The stacking tryptophan of galactose oxidase: a secondcoordination sphere residue that has profound effects on tyrosyl radical behavior and enzyme catalysis. Biochemistry. 2007;46(15):4606-18.
58. Whittaker JW. The radical chemistry of galactose oxidase. Arch Biochem Biophys. 2005;433(1):227-39.

59. Aparecido Cordeiro F, Bertechini Faria C, Parra B-T. Identification of new galactose oxidase genes in Fusarium spp. J Basic Microbiol. 2010;50(6):527-37.

60. Kersten PJ, Witek C, Wymelenberg A, Cullen D. Phanerochaete chrysosporium glyoxal oxidase is encoded by two allelic variants: structure, genomic organization, and heterologous expression of $g / x 1$ and $g / x 2$. J Bacteriol. 1995:177(21):6106-10.

61. Ito N, Phillips SEV, Stevens C, Ogel ZB, McPherson MJ, Keen JN, Yadav KDS, Knowles PF. Novel thioether bond revealed by a 1.7 $\AA$ crystal structure of galactose oxidase. Nature. 1991;350(6313):87-90.

62. Abbott DW, Eirín-López JM, Boraston AB. Insight into ligand diversity and novel biological roles for family 32 carbohydrate-binding modules. Mol Biol Evol. 2007;25(1):155-67.

63. Whittaker MM, Whittaker JW. Expression of recombinant galactose oxidase by Pichia pastoris. Protein Expression Purif. 2000;20(1):105-11.

64. Spadiut $\mathrm{O}$, Olsson L, Brumer H. A comparative summary of expression systems for the recombinant production of galactose oxidase. Microb Cell Fact. 2010;9(1):68.

65. Whittaker MM, Whittaker JW. The active site of galactose oxidase. J Biol Chem. 1988;263(13):6074-80.

66. Whittaker MM, Whittaker JW. Catalytic reaction profile for alcohol oxidation by galactose oxidase. Biochemistry. 2001;40(24):7140-8.

67. Hansch C, Leo A, Taft RW. A survey of Hammett substituent constants and resonance and field parameters. Chem Rev. 1991;91 (2):165-95.

68. Rosatella AA, Simeonov SP, Frade RFM, Afonso CAM. 5-Hydroxymethylfurfural (HMF) as a building block platform: biological properties, synthesis and synthetic applications. Green Chem. 2011;13(4):754-93.

69. Sousa AF, Vilela C, Fonseca AC, Matos M, Freire CSR, Gruter G-JM, Coelho JFJ, Silvestre AJD. Biobased polyesters and other polymers from 2,5-furandicarboxylic acid: a tribute to furan excellency. Polym Chem. 2015;6(33):5961-83.

70. Kadowaki MAS, Godoy MOD, Kumagai PS, Costa-Filho AJD, Mort A, Prade RA, Polikarpov I. Characterization of a new glyoxal oxidase from the thermophilic fungus Myceliophthora thermophila M77: hydrogen peroxide production retained in 5-hydroxymethylfurfural oxidation. Catalysts. 2018:8(10):476

71. Daou M, Yassine B, Wikee S, Record E, Duprat F, Bertrand E, Faulds CB. Pycnoporus cinnabarinus glyoxal oxidases display differential catalytic efficiencies on 5-hydroxymethylfurfural and its oxidized derivatives. Fungal Biol Biotechnol. 2019;6(1):4.

72. McKenna SM, Mines P, Law P, Kovacs-Schreiner K, Birmingham WR, Turner NJ, Leimkühler S, Carnell AJ. The continuous oxidation of HMF to FDCA and the immobilisation and stabilisation of periplasmic aldehyde oxidase (PaoABC). Green Chem. 2017;19(19):4660-5.

73. Dijkman WP, Fraaije MW. Discovery and characterization of a 5-Hydroxymethylfurfural oxidase from Methylovorus sp. strain MP688. Appl Environ Microbiol. 2014;80(3):1082-90.

74. Carro J, Ferreira P, Rodríguez L, Prieto A, Serrano A, Balcells B, Ardá A, Jiménez-Barbero J, Gutiérrez A, Ullrich R, Hofrichter M, Martínez AT. 5-hydroxymethylfurfural conversion by fungal aryl-alcohol oxidase and unspecific peroxygenase. FEBS J. 2015;282(16):3218-29.

75. Heine T, Van Berkel WJH, Gassner G, Van Pée K-H, Tischler D. Twocomponent FAD-dependent monooxygenases: current knowledge and biotechnological opportunities. Biology. 2018;7(3):42.

76. Dong J, Fernández-Fueyo E, Hollmann F, Paul CE, Pesic M, Schmidt S, Wang Y, Younes S, Zhang W. Biocatalytic oxidation reactions: a chemist's perspective. Angew Chem Int Ed Engl. 2018;57(30):9238-61.

77. Liu S, Hu W, Wang Z, Chen T. Production of riboflavin and related cofactors by biotechnological processes. Microb Cell Fact. 2020;19(1):31.

78. Moreau C, Belgacem MN, Gandini A. Recent catalytic advances in the chemistry of substituted furans from carbohydrates and in the ensuing polymers. Top Catal. 2004:27(1):11-30.

79. Rogers MS, Hurtado-Guerrero R, Firbank SJ, Halcrow MA, Dooley DM, Phillips SEV, Knowles PF, McPherson MJ. Cross-link formation of the cysteine 228 -tyrosine 272 catalytic cofactor of galactose oxidase does not require dioxygen. Biochemistry. 2008;47(39):10428-39.

80. Firbank SJ, Rogers MS, Wilmot CM, Dooley DM, Halcrow MA, Knowles PF, McPherson MJ, Phillips SEV. Crystal structure of the precursor of galactose 
oxidase: an unusual self-processing enzyme. Proc Natl Acad Sci USA. 2001;98(23):12932-7.

81. Mattey AP, Birmingham WR, Both P, Kress N, Huang K, van Munster JM, Bulmer GS, Parmeggiani F, Voglmeir J, Martinez JER, Turner NJ, Flitsch SL. Selective oxidation of n-glycolylneuraminic acid using an engineered galactose oxidase variant. ACS Catal. 2019;9(9):8208-12.

82. Grice ID, Whelan C, Tredwell GD, von Itzstein M. An approach towards the synthesis of sialyl nucleoside mimetics. Tetrahedron Asymmetry. 2005;16(8):1425-34

83. Parikka K, Tenkanen M. Oxidation of methyl a-d-galactopyranoside by galactose oxidase: products formed and optimization of reaction conditions for production of aldehyde. Carbohydr Res. 2009;344(1):14-20.

84. Pagliaro M, Rossi M. Glycerol: properties and production. In: The Future of Glycerol. Cambridge: Royal Society of Chemistry's; 2010. p. 20-1.

85. Klibanov AM, Alberti BN, Marletta MA. Stereospecific oxidation of aliphatic alcohols catalyzed by galactose oxidase. Biochem Biophys Res Commun. 1982;108(2):804-8.

86. Xia F. A novel method, and its applications, to study alcohol oxidase from Auxiliary Activity Family 5 based on direct monitoring of enzymatic reactions [MSc]. Canada: University of British Columbia; 2019.

87. Campanella JJ, Bitincka L, Smalley J. MatGAT: An application that generates similarity/identity matrices using protein or DNA sequences. BMC Bioinformatics. 2003;4(1):29.

88. Kelley LA, Mezulis S, Yates CM, Wass MN, Sternberg MJE. The Phyre2 web portal for protein modeling, prediction and analysis. Nat Protoc. 2015;10(6):845-58.
89. Larsson A. Aliview: a fast and lightweight alignment viewer and editor for large datasets. Bioinformatics. 2014;30(22):3276-8.

90. Stamatakis A. RAxML version 8: a tool for phylogenetic analysis and postanalysis of large phylogenies. Bioinformatics. 2014;30(9):1312-3.

91. Miller MA, Pfeiffer W, Schwartz T. Creating the CIPRES Science Gateway for inference of large phylogenetic trees. In: Proceedings of the gateway computing environments workshop (GCE). New Orleans, LA. IEEE; 2010. pp. 1-8

92. Lin-Cereghino J, Wong WW, Xiong S, Giang W, Luong LT, Vu J, Johnson SD, Lin-Cereghino GP. Condensed protocol for competent cell preparation and transformation of the methylotrophic yeast Pichia pastoris. Biotechniques. 2005;38(1):44-8.

93. Pettersen EF, Goddard TD, Huang CC, Couch GS, Greenblatt DM, Meng EC, Ferrin TE. UCSF Chimera - a visualization system for exploratory research and analysis. J Comput Chem. 2004;25(13):1605-12.

94. Trott O, Olson AJ. AutoDock Vina: improving the speed and accuracy of docking with a new scoring function, efficient optimization, and multithreading. J Comput Chem. 2010;31(2):455-61.

\section{Publisher's Note}

Springer Nature remains neutral with regard to jurisdictional claims in published maps and institutional affiliations.
Ready to submit your research? Choose BMC and benefit from:

- fast, convenient online submission

- thorough peer review by experienced researchers in your field

- rapid publication on acceptance

- support for research data, including large and complex data types

- gold Open Access which fosters wider collaboration and increased citations

- maximum visibility for your research: over 100M website views per year

At BMC, research is always in progress.

Learn more biomedcentral.com/submissions 